The effect of curing conditions on the hydromechanical properties of a metakaolin-based soilcrete

Giovanni Spagnoli*, Enrique Romero², Alessandro Fraccica ${ }^{3}$, Marcos Arroyo ${ }^{4}$, Rodrigo Gómez ${ }^{5}$

1 MBCC Group, Dr.-Albert-Frank-Straße 32, 83308 Trostberg, Germany, giovanni.spagnoli@mbcc-group.com, https://orcid.org/0000-0002-1866-4345, (corresponding author)

${ }^{2}$ Department of Civil and Environmental Engineering, Universidad Politècnica de Catalunya, c/ Jordi Girona, 1-3, 08034 Barcelona, Spain, https://orcid.org/0000-0002$\underline{4105-8941}$

${ }^{3}$ CIMNE, Department of Civil and Environmental Engineering, Universidad Politècnica de Catalunya, c/ Jordi Girona, 1-3, 08034 Barcelona, Spain https://orcid.org/0000$\underline{0003-4304-6765}$

${ }^{4}$ Department of Civil and Environmental Engineering, Universidad Politècnica de Catalunya, c/ Jordi Girona, 1-3, 08034 Barcelona, Spain, https://orcid.org/0000-0001$\underline{9384-9107}$

${ }^{5}$ Department of Civil and Environmental Engineering, Universidad Politècnica de Catalunya, c/ Jordi Girona, 1-3, 08034 Barcelona, Spain

\title{
ABSTRACT
}

An attractive approach to reduce the carbon footprint of deep soil mixing (DSM) is to replace Portland cement-based binders by geopolymers based on metakaolin. Safe design requires a good understanding of the mechanical and hydraulic properties of the improved ground but very little is known about metakaolin-soil mixtures. For instance, shrinkage during curing is a significant issue for metakaolin-based concretes but has not been previously studied in soilcretes. In this work the permeability and strength of sand and silty sand based metakaolin soilcretes are studied under different curing conditions. The development of microcracks induced by geopolymer shrinkage is confirmed through a microstructural study using mercury intrusion porosimetry, 
scanning electron microscopy and X-Ray computed tomography. The influence of microporosity and binder filling on permeability and strength is clarified adapting wellestablished soil models. A modified Kozeny-Carman formulation is proposed for permeability. A mixture ratio model is calibrated to represent strength. In general, the metakaolin stabilised materials present excellent mechanical and hydraulic properties, although these are very sensitive to curing conditions.

Keywords: Ground improvement, laboratory tests, sands, geopolymer, strength, permeability 


\section{ABBREVIATIONS AND SYMBOLS}

$D_{r}$

Relative density

e

Void ratio

$e_{m}$

Cumulated void ratio of micropores (in MIP)

$e_{M} \quad$ Cumulated void ratio of macropores (in MIP)

$e_{n w} \quad$ Cumulated void ratio (in MIP)

E $\quad$ Young modulus

$F_{M K} \quad$ Metakaolin filling

$F_{v, M K} \quad$ Metakaolin ratio

$G_{S} \quad$ Specific gravity

H Ground heave

$k_{w} \quad$ Permeability

MK Metakaolin

$n_{0} \quad$ Initial porosity of the soil

PSD Pore size density function

$q_{u} \quad$ Unconfined compressive strength

$\bar{q}_{u, M K} \quad$ Average unconfined compressive strength of the metakaolin

$\mathrm{R}^{2} \quad$ Coefficient of determination

RD Ranking Distance

RI Ranking Index

RMSE Root Mean Square Error

$S_{S} \quad$ Specific surface

$t_{c} \quad$ Curing day 
$v \quad$ Longitudinal wave velocity

$V_{g p} \quad$ Volume occupied by the geopolymer within the soil

$V_{M, 0} \quad$ Original macropore volume of the treated soil

$V_{t o t} \quad$ Total volume of the specimen

$\rho_{d} \quad$ Dry density

$\rho_{g p} \quad$ Bulk density of geopolymer

$\rho_{s} \quad$ Density of the solid particles

$\rho\left(t_{c}\right) \quad$ Density of the sample at the corresponding curing day

C, $\alpha, \beta \quad$ Parameters of the hydraulic model

$Q, D \quad$ Parameters of the mechanical model

$\gamma \quad$ Parameter of the $\Delta \mathrm{e}$ model 


\section{INTRODUCTION}

Ground improvement aims to enhance engineering properties of soils such as strength, stiffness or permeability. In deep soil mixing (DSM) soil and binders are mixed in place by mechanical means to form a material often referred to as soilcrete. In DSM applications (e.g. Larsson, 2003; Rutherford et al. 2005; Topolnicki, 2012; Bruce et al. 2013; Spagnoli et al., 2014; Bellato et al., 2015; Doherty et al., 2016; Bellato et al., 2020) treatment units such as columns or panels of soilcrete are combined to form structural elements (slabs, walls, foundation blocks...). To date the large majority of DSM treatments are formed using Ordinary Portland Cement (OPC) as binder. However, cement manufacturing accounts for $8 \%$ of global $\mathrm{CO}_{2}$ emissions and reducing the carbon footprint of concretes is increasingly urgent (International Energy Agency 2018). Low-carbon binders in which OPC has been totally substituted are seen as key to achieve significant long-term reductions (Lehne \& Preston, 2018).

Alkali-activated binders $(A A B)$ are resulting from the reaction of a solid alumino-silicate based material (precursor) and an alkaline metal (activator, e.g. $\mathrm{NaOH}, \mathrm{Na}_{2} \mathrm{SiO}_{3}$ ). Concrete or stabilised soils with $A A B$ are generally capable of attaining similar performances as Portland-based cements with much reduced carbon emission (Provis and Deventer, 2014). They have excellent mechanical properties (e.g., compressive strength and stiffness) and exceptional resistance to heat, organic solvents and acids.

A variety of products can act as precursors in AAB. Important examples include industrial wastes such as ground blast-furnace slag (GBFS) or fly-ash residue from coalfired electricity generation as well as natural products, such as volcanic ash or a calcined kaolinite known as metakaolin.

AAB such as slag produce CSH gel as the reaction product, similar to OPC-based binders but typically with a lower $\mathrm{Ca} / \mathrm{Si}$ ratio (e.g. Yip et al., 2005). Metakaolin and lowcalcium fly-ash result in almost exclusively aluminosilicate AABs, which are generally known as geopolymers (Davidovits, 1994; Provis \& Bernal, 2014). Metakaolin has some potential advantages as precursor for AABs. It is an industrial product, generally having more consistent properties than residue-based $A A B$. The raw material (clay) is abundant (IEA, 2018) and, unlike some residues, will not be limited by foreseeable changes in technology (as is the case of GGBS) or in the energy production mix (as is the case of FA). On the other hand, the current production of metakaolin is still small and it is currently marketed at significantly higher prices per weight that OPC or other 
AAB precursors. The comparative advantages of different $A A B$ are, however, strongly dependent on local circumstances (Arrigoni et al. 2020).

There are also some difficulties associated with metakaolin-based binders. They are highly viscous (Provis \& Bernal, 2014), which makes them unsuitable for soil injection purposes and better adapted for deep-mixing. Shrinkage and sensitivity to curing conditions are relevant issues for most $A A B$, but particularly so for metakaolin-based binders. Curing of metakaolin geopolymer at ambient temperature is accompanied by shrinkage and cracking (Kuenzel et al. 2012). This is related to two material characteristics. First, the plate-like particle shape of metakaolin imposes relatively high water demands for workability (Provis and Deventer, 2014). Second, as opposed to Portland based binders, water is not bound within the structure of metakaolin geopolymers, which facilitates evaporation.

There is limited scope for controlled curing conditions in DSM. The treated soil and its surroundings need not be saturated or underwater. In some applications, such as retaining walls, the soilcrete might be quickly exposed to the atmosphere. These considerations have motivated researchers to look at the effect of curing conditions on Portland-based (Mossadegh et al. 2017) and hydraulic binders (Le Kouby et al. 2018) but they have not yet been considered for geopolymers.

The application of alkali-activated binders to soil improvement has received some attention. However, most of this work has used precursors other that metakaolin, like fly ash (e.g. Cristelo et al., 2011; Cristelo et al., 2013; Rios et al., 2016; Liu et al., 2016; Rios et al., 2017; Arulrajah et al. 2018; Murmu et al., 2019), GBFS (Sargent et al., 2013; Singhi et al., 2016) or volcanic ash (Verdolotti et al., 2008; Ghadir and Ranjbar, 2018).

Metakaolin is a dehydroxylated aluminium silicate $\left(\mathrm{Al}_{2} \mathrm{O}_{3} \cdot 2 \mathrm{SiO}_{2}\right)$ resulting from calcination and micronisation of kaolinitic clay. It is an amorphous material with lamellarshaped particles. Studies in which a metakaolin-based geopolymer is used to improve soil properties are scarce. Several researchers have assessed the use of metakaolin in soil treatment as a partial Portland substitute (Kolovos et al 2013; Deng et al. 2015; Wu et al. 2016; Asteris et al. 2017; Wang et al. 2018), but they used no alkali activators and, therefore, the resulting binders were not geopolymers. Zhang et al (2014) presented a feasibility study, in which a clay was mixed with several metakaolin based 
geopolymers. The strength attained by mixtures at $5.5 \% \mathrm{w} / \mathrm{w}$ metakaolin was similar to that attained with $5 \%$ OPC. The geopolymer-stabilized samples were more ductile and effective in restraining clay retraction than OPC. They observed no increase in strength of the MK-improved soils during a 28-days curing period.

To our knowledge this is the first study addressing metakaolin-based geopolymer treatment of granular soils. The work explores the effect of treatment on permeability, strength and stiffness using a microstructural perspective to clarify the macroscopic observations.

\section{MATERIALS AND METHODS}

\section{Base materials}

Two different model soils were selected for treatment with metakaolin geopolymer. The first one is a medium quartz sand (Holcim 0.2-0.6 mm); the second is a silty sand obtained by dry mixing a pure carbonate silt $\left(\mathrm{CaCO}_{3}\right.$ Omyacarb $\left.\AA^{8} 40\right)$ with Holcim sand. In the later the carbonate silt/sand ratio is $10 \%$ by weight. Chemical and physical properties of the sand, silt and silty sand mixture are summarised in Table 1

The binder used is an alkali-activated metakaolin. XRF analyses showed a composition of $55 \% \mathrm{SiO}_{2}, 40 \% \mathrm{Al}_{2} \mathrm{O}_{3}$, and $\mathrm{Fe}_{2} \mathrm{O}_{3}$ and $\mathrm{TiO}_{2}$. This is in line with the results of other studies (Velosa et al. 2009; Panesar, 2019) showing that the main constituents of metakaolin are $\mathrm{SiO}_{2}$ and $\mathrm{Al}_{2} \mathrm{O}_{3}$ although the detailed composition might vary slightly according to the specific sources of kaolin employed. The metakaolin is activated with a highly alkaline water solution of potassium silicate $\left(\mathrm{w}\left(\mathrm{SiO}_{2}\right) / \mathrm{w}\left(\mathrm{K}_{2} \mathrm{O}\right)=1\right)$. Potassium silicate, water and metakaolin are mixed in equal weights, leading to a Si/Al ratio of 1.3 and a fluid/metakaolin (F/MK) mass ratio 2:1. This ratio, which controls flowability of the binder, is analogous to the water/cement ratio $(\mathrm{W} / \mathrm{C})$ in classical Portland based binders. W/C ratios of 2 are used, for instance, to create cut-off walls in deep mixing applications (e.g. Puppala et al., 2008; BAUER Maschinen GmbH, 2016).

\section{Specimen preparation}

An overview of the testing program is given in Table 2. Test were performed on specimens of pure metakaolin geopolymer (MK), on the base soils (S: sand, SO: sand+ carbonate silt) and on two soil-geopolymer mixtures (SMK: sand+metakaolin, SOMK: sand+carbonate silt+metakaolin). 
All specimens were prepared by pouring the soils or soil-geopolymer mixtures into moulds. Two different specimen sizes were used. UC-size specimens with 70-mm diameter and $164 \pm 10 \mathrm{~mm}$ height were prepared for unconfined compression tests, (ASTM 2166- 2016). TX-size specimens, with $38 \mathrm{~mm}$ diameter and $96 \mathrm{~mm}$ height were prepared and subsequently sanded to ensure smooth faces following ASTM D4767 - 11 (2020) and ASTM D5084 (2016), respectively, for permeability measurements and non-destructive testing.

The binder slurry was stirred in a mechanical mixer for at least 5 minutes, continuing until reaching a lumps-free dispersion of density $1.37 \mathrm{Mg} / \mathrm{m}^{3}$ which was then handmixed with the soils. The resulting binder-soil mixture was gently poured in cylindrical steel moulds and then lightly levelled and -for the TX specimens- slightly compacted with a piston. Air bubbles were removed from geopolymer-soil mixes during casting, by lightly hitting the moulds with a rubber hammer while inspecting the upper face of the specimens.

Two different protocols were used for curing. Dry curing (D) describes specimens cured at room conditions of $20^{\circ} \mathrm{C}$ and $50 \%$ of relative humidity $(\mathrm{RH})$. Wet curing (W) describes specimens cured by immersion in water at $20^{\circ} \mathrm{C}$. Immersion started after three days after pouring the specimens, when they had enough consistency to be extracted from the moulds. Testing took place after for 3, 7 and 28 days of curing. Before carrying out the tests, the ends of the sample were trimmed with a diamond band saw and then sanded to ensure orthogonal faces to the longitudinal axis. Heat curing was not undertaken as it is not considered a practicable alternative for in-situ soil treatments (Abdullah et al., 2020).

Because of the emphasis on permeability of the testing program, the mixture definition was not simply based on weight, but focused instead on the porosity filling role of the geopolymer within the base soils. Pouring of Holcim sand resulted in a relative density $\mathrm{Dr}=35 \%$, which corresponds to a void ratio $\mathrm{e}=0.825$. The $10 \%$ by weight of carbonate silt in the silty sand results in an underfilled packing. Assuming that both soil fractions in the mixture maintain the as-poured bulk density reported in Table 1, the silt would fill $29 \%$ of the voids within the sand skeleton (complete filling would require a silt/sand weight ratio of $34 \%$ ). The silty sand as-poured void ratio is 0.584 . 
Maintaining a fixed mass of Holcim sand (158.1 $\mathrm{g}$ for TX-size; $902.0 \mathrm{~g}$ for UC-size) the amount of binder slurry added to the mix was selected as enough to fill either a $100 \%$ or a $40 \%$ of the initial as-poured porosity of the soils. This is subsequently referred to as the initial geopolymer filling ratios and denoted by $F_{M K, 0}$. The resulting weight ratios employed in the TX-and UC-sizes at the different volumetric $F_{M K, 0}$ targets are summarised in Table 3.

The following nomenclature is used to identify the samples. The first letters indicated the composition: MK: pure metakaolin, S: sand, SO: sand + carbonate silt, SMK: sand + metakaolin, SOMK: sand + carbonate silt + metakaolin. The number in parenthesis indicated the target void filling with the metakaolin geopolymer $\left(F_{M K, 0}\right)$. The curing condition is indicated by a letter ( $\mathrm{W}$ for water immersion; $\mathrm{D}$ for $50 \% \mathrm{RH}$ ) and a number (3, $7,14,28)$ indicating the curing time, in days. For instance, a sample of sand treated with an initial geopolymer filling equal to $100 \%$ of the pore volume, tested after 28 days of curing at $50 \% \mathrm{RH}$, would be $\mathrm{SMK}(100) \mathrm{D} 28$.

\section{Microstructural analyses}

Field Emission Scanning Electron Microscopy (FESEM) analyses were carried out in a JEOL JSM-7001F microscope. Samples for FESEM, with an average size of $5 \mathrm{~mm}$, were carefully trimmed from TX-size specimens and then coated with a conductive metallic layer before the observation.

Mercury Intrusion Porosimetry (MIP) tests were carried out in an AutoPore IV 9500 porosimeter. 10-mm size cubes were carefully trimmed from treated TX-size samples by a bandsaw, and their mass and water content determined by oven-drying.

MIP results are expressed in terms of the intruded volume of mercury referred to the volume of solids (intruded void ratio $e_{n w}$ ) for different entrance pore sizes $x$. These are determined from the applied absolute mercury pressure using Washburn equation with surface tension $0.484 \mathrm{~N} / \mathrm{m}$ and a contact angle of $140^{\circ}$. Further details of the technique are described in Romero and Simms (2008).

\section{X-ray inspection}

There were some initial doubts about how homogeneous the poured specimens of soilgeopolymer would be, with segregation a possibility. An X-ray CT scanner (Siemens 
Somatom Spirit(B) was used to confirm this homogeneity. X-ray voltage was $130 \mathrm{kVp}$ and tube current was $34 \mathrm{~mA}$, voxel size was of $0.34 \times 0.34 \times 1 \mathrm{~mm}^{3}$. The tomographic images were also used to determine the bulk density of different treated soil specimens as well as that of the pure geopolymer. Bulk density was obtained from the image grey value after calibration with a set of reference samples of known density (two sand samples at different relative densities, one sample of carbonate silt as poured, one glass sphere). The calibration curve thus obtained was $\left(R^{2}=0.98\right)$.

$\rho=8 \times 10^{-4} G V+0.806$

where $\rho$ is the bulk density $\left(\mathrm{Mg} / \mathrm{m}^{3}\right)$, and GV (-) is the average grey value of the corresponding material image. The density resolution of the scan was $0.016 \mathrm{Mg} / \mathrm{m}^{3}$. The scanner bulk density results were contrasted and complemented with standard measurements using the paraffin method (ASTM 7263 - 18).

\section{Hydraulic and mechanical tests}

The saturated permeability, $k_{w}$, of $\mathrm{S}$ and $\mathrm{SO}$ was evaluated with a rigid wall permeameter (ASTM D5856 - 15) with local measurements of pore pressure. Based on the grain size distribution curves presented in Spagnoli et al. (2020), the risk of silt migration in the SO specimen was excluded according to a well-established filter design criterion ( $D_{15}<4 d_{85}$; Terzaghi et al., 1996). The permeability of soil-geopolymer mixtures was measured in a triaxial cell under controlled gradient (ASTM D5084 - 16). Treated samples under a confining stress $200 \mathrm{kPa}$ were saturated by applying back pressure at the bottom $(100 \mathrm{kPa})$ and lower pressure at the top $(10 \mathrm{kPa})$. Inflow and outflow water volumes were monitored by automatic pressure/volume controllers, until steady-state conditions (equivalent inflow and outflow volume rates) were attained for permeability measurements.

Unconfined compressive strength (UCS) tests were carried out according to ASTM D2166 (2016). Compression was imposed by a controlled displacement-rate of $0.60 \mathrm{~mm} / \mathrm{min}$ (axial deformation rate around $0.5 \% / \mathrm{min}$ ). All specimens had height-diameter ratios between 2 and 2.5 at a fixed diameter of $70 \mathrm{~mm}$, except for some MKD samples with slightly smaller diameter due to demoulding problems. The secant Young modulus at different axial strains was also obtained from UCS tests. 
Small-strain stiffness was assessed by measuring elastic bar wave velocity (Amaral et al. 2011) on MK and SMK specimens. An Ultrasonic Pulse Velocity Tester (Proceq Pundit Lab Lab+) was used jointly with a couple of piston transducers $(54 \mathrm{kHz})$ positioned on the flat ends of each specimen (ASTM C597 - 16). A coupling gel was used at the transducer contact. At each measurement point four readings of travel time were taken and averaged. The bar wave velocity, $v_{b}$, was calculated considering the specimen height. The small-strain Young modulus, $E$, was calculated at a given curing time $t_{c}$ as:

$E=\rho\left(t_{c}\right) v_{b}^{2}$

where $\rho\left(t_{c}\right)$ is the bulk density at the corresponding curing time $t_{c}$.

\section{RESULTS}

\section{Evolution of metakaolin geopolymer during curing}

Specimens of metakaolin geopolymer increased their void ratio by up to $50 \%$ during the curing period as shown in Figure 1a. The porosity appearing in the metakaolin geopolymer may be interpreted as the result of fissuring during shrinkage. Shrinkage cracks were evident in MKD specimens (Figure 1b-c-d) but not so in those cured under water. This cracking strongly affects the apparent or bulk density of the specimens, which reduces during curing. After 28 days of curing MKD density reduces by $30 \%$ to reach values close to $1 \mathrm{Mg} / \mathrm{m}^{3}$.

Pore size distributions (cumulative and log-density) resulting from MIP of pure geopolymer specimens at different curing conditions are shown in Figure 2. The pore sizes range in between $7 \mathrm{~nm}$ and $1 \mu \mathrm{m}$. In all cases a dominant pore mode can be identified close to $20 \mathrm{~nm}$ (the peak value is reported in Table 4 as $x_{\text {m,peak }}$ ). These dominant modes appear at larger sizes in the specimens cured in dry condition (MKD) than in those immersed (MKW). Dry curing always results in more pores, as shown by the cumulated void ratio Figure 2a. Total intruded porosity in MKW specimens was slightly below that measured by either paraffin or X-ray (Figure 1a) which indicates the presence of some occluded pores (i.e. small bubbles) in the material.

The pore sizes that appear in the geopolymer during curing are far smaller than those initially present in the treated soils (Figure 3). By establishing a threshold value of 1 
$\mu \mathrm{m}$ this large difference is later exploited when considering results of treated speci-mens, to separate micropores inside the geopolymer and macropores corresponding to intergranular porosity.

Unconfined compressive strength for MK samples (both cured at dry and wet conditions) is reported in Table 5. The $q_{u}$ values decrease during the curing period. The decrease was abrupt for MKD, to the extent that it was not possible to carry out the UCS test on MKD at 28 days due to fragmentation and fissuring. Wet curing slightly decreased the ductility of the geopolymer, as measured by the ratio $E_{\text {sec50 }} / q_{u}$, whereas this value increased for dry curing.

The small strain stiffness of MK specimens was much higher for those cured under water than for those cured dry (Figure 4). A slight increasing trend with time is visible for dry curing, whereas the results for wet curing appear more erratic, with a sudden jump after 10 days.

\section{Evolution of geopolymer treated soils during curing}

The void ratio evolution of geopolymer treated soils during curing is shown in Figure 5. The results show a small increase, but far below than what was observed for the geo-polymer alone. Similarly to sand-geopolymer mortars (Kuenzel et al. 2014) the granular skeleton dominates the overall volumetric response and partially restrains geopolymer shrinkage. However, this relative stability of the total void ratio does not mean that there are no changes in the pore size distributions. In the same figures, the void ratio values that the soils would have had if the geopolymer did not shrink at all are pre-sented. These values were calculated by evaluating the geopolymer volume within the treated soils, knowing its dry mass and its density of solid particles.

Porosity distribution of SMK specimens are illustrated in Figure 6. In these plots two different dominant pore modes are evident. Using the $1 \mu \mathrm{m}$ threshold value, the in-truded void ratios detected by MIP can be separated into a microvoid ratio $e_{m}$ inside the MK geopolymer and a macrovoid ratio $e_{M}$ between cemented sand grains. Values of $e_{m}$ and $e_{M}$ as well as the peak modal values of porosity ( $x_{m \text {,peak }}$ for the lower mode and $x_{M \text {,peak }}$ for the upper mode) are summarised in Table 4 for the different mixtures.

The pore distribution is affected by curing conditions. Wet curing resulted in a decrease in macropore volume. Dry curing (compare SMK(100)D3 to SMK(100)D28 in Figure 6) 12 
resulted in a clear increase in macropore volume and a slight reduction in total micropore volume as the lower mode distribution became sharper.

For the same dry curing condition, the presence of the carbonate silt results in increased porosities both in the micropore and in the macropore range (see Figure 7). The carbonate silt also shifted towards larger values the macropore modal peak. As a result, the macropore and micropore fractions are more equilibrated in SOMK specimens, whereas micropores were always dominant for SMK.

The FESEM results offer some insight into the observed microstructural differences. Images of SO samples at different magnifications (Figure 8) reveal that carbonate silt appears to coat the sand grains rather than fill voids between grains. This phenomenon conditioned the response of SOMK samples. As observed in Figure 9, the sample with silt (SOMK(100)D28) presented larger relative motions and separation between sand grains than the sample without silt (SMK(100)D28). The FESEM images also make visible the highly fissured state of the MK between sand grains.

The observed geopolymer damage can be related to the unconfined compressive strength of the treated soils reported in Table 5. For the SMK specimens $q_{u}$ reduces with time and is higher for wet curing. For SOMK specimens at $\mathrm{RH}=50 \%$ the $q_{u}$ values appear to be more stable. The secant Young moduli, $E_{s e c}$, at different axial strains, $\varepsilon_{1}$,

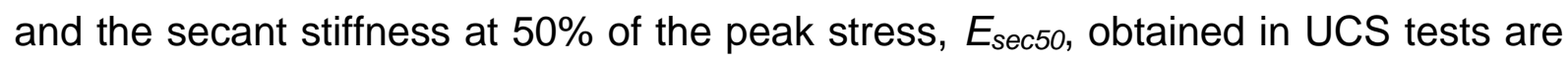
also presented in Table 5. For the SMK specimens, dry curing results in a marked decrease of medium-strain stiffness, while wet cured specimens were stiffer and showed no decrease in time. Adding silt in the mixture also resulted in a stiffer performance (compare results for SMK(100)D and SOMK(100)D).

Figure 10 summarises small-strain stiffness results as a function of curing time for SMK(100)D and SMK(100)W specimens. This small strain measure of stiffness increased by $60 \%$ for dry-cured specimens, whereas it did so by $275 \%$ for the wet-cured ones. It appears that the geopolymer-bound soil is stiffer than the pure binder.

Table 4 reports the permeability values obtained for the different materials. Geopolymer treatment achieved a reduction of permeability between 2 and 5 orders of magnitude from that of the original soils. 
Although starting from a very low level, the permeability of those specimens with higher geopolymer dosage (SMK(100)D, SOMK(100)D) increased by one order of magnitude during the curing period, whereas those improved with the lower geopolymer dosage $\left(F_{M K, 0}=40 \%\right)$ were more stable. These changes upon curing resulted on a marked convergence in permeability between the low and high dosage specimens.

\section{Evolution of geopolymer filling during curing}

As stated above, the mixtures were designed so that the binder slurry would fill a given fraction of the initial void ratio of the host soil. However, such fraction needs to be recomputed during curing because of geopolymer shrinkage and cracking.

Phase diagrams in Figure 11 are helpful to visualise the involved phenomena. At time to metakaolin powder and the sodium silicate solution are mixed. Precursor and activator react to form the geopolymer. Cracks (microporosity, $V_{M}$ ) appear during curing as the geopolymer changes volume. In dry curing conditions some water evaporates and some water remains within the geopolymer pores. In wet curing conditions the micropores are always filled with water.

In the treated soils the overall volume is constant and the geopolymer -which includes developing micropores- is partly filling the initial macropore space $\left(V_{M, 0}\right)$. The volume occupied by the geopolymer $V_{g p}$ within the soil is computed as:

$$
V_{g p}=\frac{M_{g p}}{\rho_{g p}}=\frac{\rho V_{t o t}-M_{S}}{\rho_{g p}}
$$

where $M_{s}$ is the mass of the soil particles, $\rho_{g p}$ and $\rho$ are respectively the bulk density of geopolymer and treated soil at given curing conditions, and $V_{\text {tot }}$ the total volume of the specimen. In the test specimens $M_{s}$ is a fixed quantity, $\rho_{g p}$ for any particular curing condition is assumed equal to that observed in the MK experiments, and $\rho$ and $V_{\text {tot }}$ are directly measured in the treated soil.

The geopolymer void filling ratio may be then computed as:

$$
F_{M K}=\frac{V_{g p}}{V_{M, 0}}
$$

where $V_{M, 0}$ is the original macropore volume of the treated soil. The values of this filling ratio are reported in Table 4 -for TX specimens- and Table 5 -for UCS specimens. It 
can be seen that the geopolymer filling ratios actually attained are well below the slurry filling ratios, $F_{M K, 0}$. With a slurry filling ratio of $100 \%$ the geopolymer left only fills between $49 \%$ and $79 \%$ of the initial voids. With a slurry filling ratio of $40 \%$ the geopolymer left fills only between $21 \%$ and $34 \%$ The presence of silt reduces the geopolymer filling ratio, dry curing does the same.

Normalising by the specimen total volume it turns out that the geopolymer void filling ratio also expresses the ratio between geopolymer volumetric ratio, $F_{v, M K}$ and the original soil porosity, $n_{0}$ :

$$
F_{M K}=\frac{\frac{V_{g p}}{V_{t o t}}}{\frac{V_{M, 0}}{V_{t o t}}}=\frac{F_{v, M K}}{n_{0}}
$$

As discussed below, the inverse of this ratio has some similarities with some frequently employed porosity/binder ratios (Consoli et al. 2012).

\section{DISCUSSION}

\section{Relation of permeability to microstructural features}

Different expressions can be considered to fit the permeability data reported in Table 4 and incorporating microstructural information besides the porosity. For example, Deng et al. (2015) correlated the permeability of a marine clay stabilised with OPCmetakaolin binders to porosity data and median throat pore size obtained by MIP. The soils studied by these authors displayed either monomodal PSDs or bimodal PSDs for which dominant pore size modes were within one order of magnitude. This is not the case for the mixtures addressed in this work (refer to Figure 6 and Figure 7).

A modified expression of the Kozeny-Carman model (Kozeny, 1927; Carman, 1956) was used to interpret the permeability values. Kozeny-Carman -or simply KC-formulations have been successfully employed to incorporate microstructural effects derived from particle shape in granular soils (e.g. Nguyen \& Indraratna, 2020) or porosity distribution in compacted bentonite (Chen et al., 2020). Microstructural effects in KC might be implemented through tortuosity (e.g. Ghanbarian et al., 2013), porosity or both. A particular feature of this case was the need to account for very significant reductions (five orders of magnitude) of permeability as geopolymer filling increased.

The modified KC expression that was finally adopted to express permeability $k_{w}$ is: 
$k_{w}=C \frac{\rho_{w} g}{\mu_{w}} \frac{n^{\beta}}{\left[\frac{S_{S} \rho_{s}}{\left(S_{s} \rho_{S}\right)_{S}}(1-n)\right]^{\alpha}}$

where $\rho_{w} g / \mu_{w}=9.8 \times 10^{6}(\mathrm{~m} \cdot \mathrm{s})^{-1}$ is the water property factor at $20^{\circ} \mathrm{C}$ (water density $\rho_{w}=$ $998 \mathrm{~kg} / \mathrm{m}^{3}$, acceleration of gravity $g=9.8 \mathrm{~m} / \mathrm{s}^{2}$ and water dynamic viscosity $\mu_{w}=$ $\left.1.0 \times 10^{-3} \mathrm{~N} \cdot \mathrm{s} / \mathrm{m}^{2}\right) ; n$ is the porosity of the treated soil, $\rho_{s}$ is the density of solids of each treated material; $S_{s} \rho_{s}$ is the specific surface per unit volume of solids, $\left(S_{s} \rho_{s}\right)_{S}$ is a reference value taken as that of the host sand. The adjustment parameters of the model are $\alpha, \beta$ and $C$. $C$ is not only affected by conventional parameters such as the pore shape factor and the tortuosity/connectivity of the pathways, but also by the reference value $\left(S_{s} \rho_{s}\right)_{S}$ (i.e. the reference specific surface per unit volume of solids of the sand).

The $S_{s}$ values value can be obtained from MIP measurements assuming cylindrical pores (Romero, 1999). MIP results -and thus specific surface- were not available for all specimens for which permeability had been measured. However, specific surface values in the mixtures are likely to reflect the content of geopolymer, because $S_{s}$ values for metakaolin are orders of magnitude above those of the soils in the mixture (see Table 1 and Table 4). This connection explains the very good correlation observed between the specific surfaces $S_{s} \rho_{s}$ normalised by the reference value of the sand $\left(S_{s} \rho_{s}\right)_{s}$ and the geopolymer void filling ratio (Figure 12). The correlation is expressed by:

$F_{M K}=0.043\left[\frac{s_{s} \rho_{s}}{\left(S_{s} \rho_{s}\right)_{S}}-1\right]^{0.36}$

This expression was used to estimate the specific surface values (per unit mass of solids) reported in Table 4 for specimens for which MIP was not available. The values obtained for the different state variables are summarised in Table 4.

Using the values reported in Table 4, Equation (6) was fitted minimising the mean squared logarithmic error (MSLE). The fit was good $\left(\mathrm{R}^{2}=0.98\right)$ using parameters $\alpha=$ 1.34, $\beta=2.74$ and $C \frac{\rho_{w} g}{\mu_{w}}=4.62 \times 10^{-3} \mathrm{~m} / \mathrm{s}$. In a classical $\mathrm{KC}$ formulation the value of $\beta$ would be 3 and that of $\alpha$ would be 2 . The larger discrepancy is thus in the value of $\alpha$ and could be considered as an additional contribution of the tortuosity/connectivity of the water pathways. This tortuosity/connectivity is expected not only to be affected by 
the porosity but also by the important change introduced by the partial filling of pores with metakaolin.

Figure 13 presents the permeability results as a function of the porosity of the treated soil, with isolines of constant geopolymer void filling ratio plotted using Equations (6) and (7). As noted above, the modified KC expression adequately fitted the experimental data -labelled with their $F_{M K}$ values. The important role played by geopolymer filling in controlling mixture permeability is evident in Figure 13.

In Figure 14, the unconfined compression strength results are plotted together with permeability results with $F_{M K}$ values presented as labels. As observed, increasing values of $F_{M K}$ induced a consistent increase in compressive strength and a reduction in permeability.

\section{Strength: geopolymer-improved vs cement-improved sand}

Consoli and co-workers $(2010 ; 2011 ; 2017)$ have shown how the strength of sands improved with Portland cement may be accurately described by power relations such as

$$
q_{u}=B\left[\frac{\eta}{C_{i v}}\right]^{-A}
$$

Where $\eta$ is the porosity of the mixture and $C_{i v}$ is the volumetric cement content (both computed with the dry cement powder) and their ratio is referred to as the porosity/cement index. A and B are empirical parameters that depend on both soil and binder characteristics as well as curing time.

Assuming that the metakaolin powder plays a similar role to the cement powder, a porosity/binder index may be computed for the UCS specimens (see Table 5). Instead, Figure 15a compares the relations that were obtained for mixtures of different Portland cements and Osorio sand (a poorly graded quartz sand, similar to Holcim sand) after 7 days wet curing with the $q_{u}$ values of SMK(100)W. This result for granular soils confirms something already noted by Zhang et al (2014) for clays: geopolymer improved soils may attain similar strengths to Portland -improved soils at similar dosages.

However, the similarity with the Portland case breaks down when the evolution during curing is considered. As shown in Figure 15b, wet curing increases significantly the 
strength of Portland-improved sand over that available at 7 days, something that is not the case for the geopolymer improved soil.

The range of the porosity/binder ratio in the tests is rather narrow (5-7\%) and a direct fit of equation (8) did not provide meaningful results. Instead a reasonable fit (Figure 16 ) was obtained between the geopolymer void filling ratio and the normalised mixture strength

$$
\frac{q_{u}}{\bar{q}_{u, M K}}=Q\left(\frac{n_{0}}{F_{v, M K}}\right)^{D}=Q\left(\frac{1}{F_{M K}}\right)^{D}
$$

where the normalizing factor $\bar{q}_{u, M K}$ is the average strength of pure metakaolin specimens and $Q$ and $D$ are fitting parameters (for the specimens tested here $Q=2.3 ; D=$ $-1.35)$.

\section{Estimating "as treated" field properties}

The observations made during this laboratory campaign might be used to guide future field experiments in geopolymer-based DSM. For instance, to estimate the treated soil permeability according to Figure 13 the geopolymer void filling ratio $F_{M K}$ and the as treated soil porosity are required. As indicated in Figure 11 these two properties are different from the easily accessible initial soil void ratio $e_{0}$ and the initial metakaolin slurry filling $F_{M K, 0}$ To relate these initial values and the as treated values some auxiliary variables are needed.

It is a common observation (Kitazume and Terashi, 2013; Karstunen, 2014) that DSM treatments result in some soil heave, with heave values up to several decimeters. Heave magnitude depends on the soil profile and technological details such as the mixing tool, the mixing condition (dry or wet mix) or the installation sequence in the treatment area. For a given mixing technology heave is highly dependent on the volume of binder slurry added to the soil (Kitazume and Terashi, 2013). These observations are formalized here using the variable $H$, expressed as:

$H=\frac{\Delta V_{t o t}}{V_{g p, 0}}=\frac{V_{t o t, f}-V_{t o t, 0}}{V_{g p, 0}}=\frac{V_{t o t, f}-V_{t o t, 0}}{F_{M K, 0} V_{M, 0}}$

The experiments presented above also gave clear indication that a substantial amount of geopolymer shrinkage is to be expected. Figure $16 \mathrm{~A}$ geopolymer-shrinkage ratio may thus be defined as 
$\gamma=\frac{F_{M K, 0}}{F_{M K}}$

As shown in the Appendix it is possible, using these two auxiliary variables, to relate the initial and as treated void ratios, through the following expression

$\Delta e=e_{0}-\mathrm{e}=f\left(e_{0} ; F_{M K, 0} ; n_{g p} ; H ; \gamma\right)=\frac{\left(1-n_{g p}-\gamma H+\left(1-n_{g p}\right) e_{0}\right) \frac{F_{M K, 0}}{\gamma} e_{0}}{1+\left(1-n_{g p}\right) \frac{F_{M K, 0}}{\gamma} e_{0}}$

where $n_{g p}$ is the porosity of the geopolymer.

Considering now, for instance, a case of dry curing. At 28 days the average value of $n_{g p}$ is close to 0.33 (from MIP results in Table 4), and $\gamma=1.75$ may be estimated as an intermediate average value between those for sand (1.6) and silty sand (1.9). We can therefore plot Eq (12) as a relation between $\Delta \mathrm{e}$ and $F_{M K, 0}$ for different values of the heave index $H$ (Figure 17).

For the simply poured specimens of the experimental campaign the heave was $H=0$ -no overall volumetric deformation during treatment- and the points fall close to that isoline (with errors due to the simplifying average values taken for $\gamma$ and $n_{g p}$. Kitazume and Terashi (2013) suggest that a ground heaving ratio, $H=0.70$ is representative for practical in situ applications. For this value Figure 17 suggest that the geopolymer filling effect and the heave induced by mechanical mixing will almost exactly compensate and the void ratio of the treated soil will be very close to that of the original soil. That would facilitate estimates of resulting permeability (using Figure 13) or strength (using Figure 16).

\section{CONCLUSIONS}

This work has presented the first study of granular soils treated with a pure metakaolinbased geopolymer, with no addition of OPC. The study has confirmed that metakaolin geopolymers are prone to shrinkage. Because of cracking induced shrinkage metakaolin geopolymer alone loses all cohesion upon dry curing; upon wet curing there is still damage, although far less severe.

Shrinkage and cracking of metakaolin geopolymer does also take place when it is mixed with granular soils, however the effects on porosity and strength are much smaller than those observed on the isolated geopolymer. There is a mutually beneficial 
interaction between granular skeleton and the geopolymer. The granular skeleton shields the geopolymer and the geopolymer bounds the grains. Similar strengths to Portland-based cement may be attained at similar weight dosages, although, contrary to Portland the strength will not improve in time.

Even if cracked, the presence of geopolymer within the pores of the granular skeleton results in effective soil impermeabilization. The key role of effective geopolymer filling in this respect was clarified using an adapted Kozeny-Carman model. The geopolymer void filling ratio was also clearly linked to the strength of the soil-geopolymer mixtures.

The results presented support the consideration of metakaolin-based geopolymers as a plausible alternative to reduce the carbon footprint of deep soil mixing treatments. The results presented also suggest that applications below the water table or in saturated soil should be initially favoured, to avoid shrinkage and associated material degradation. However more research is needed to clarify the effect of curing under intermediate -more realistic- levels of relative humidity (i.e. above the very dry $50 \% \mathrm{RH}$ condition that was employed here). Another important aspect that needs to be explored is the effect of curing under stress, as treated soils will cure under the in situ stress, in conditions that are likely to reduce total porosity, pore size and, consequently, shrinkage.

Follow-up studies in the laboratory and the field will hopefully benefit from the concepts and results presented in this work.

\section{ACKNOWLEDGEMENT}

The authors wish to thank Master Builders Solutions by MBCC Group for the permission granted to publish the results.

\section{APPENDIX}

Aiming for an expression of $e$ as function of $e_{0}, F_{M K, 0}, \gamma, H$ and $n_{g p}$, the following identities are useful:

$$
\begin{aligned}
& V_{m}=n_{g p} V_{g p}=n_{g p} F_{M K} V_{M, 0}=n_{g p} \frac{F_{M K, 0}}{\gamma} V_{M, 0} \\
& V_{b}=V_{t o t}-V_{S}-V_{M}-V_{m}
\end{aligned}
$$


$V_{t o t}=V_{t o t, 0}+H V_{g p, 0}$

$V_{g p, 0}=F_{M K, 0} V_{M, 0}$

According to Figure 11:

$e=\frac{V_{m}+V_{M}}{V_{S}+V_{b}}$

substituting, step by step:

$e=\frac{n_{g p} \frac{F_{M K, 0}}{\gamma} V_{M, 0}+V_{M}}{V_{S}+V_{t o t}-V_{S}-V_{M}-V_{m}}$

$e=\frac{n_{g p} \frac{F_{M K, 0}}{\gamma} V_{M, 0}+V_{M}}{V_{t o t}-V_{M}-V_{m}}$

$e=\frac{n_{g p} \frac{F_{M K, 0}}{\gamma} V_{M, 0}+V_{M}}{V_{t o t, 0}+H F_{M K, 0} V_{M, 0}-V_{M}-n_{g p} \frac{F_{M K, 0}}{\gamma} V_{M, 0}}$

$e=\frac{V_{S}}{V_{S}} \frac{n_{g p} \frac{F_{M K, 0}}{\gamma} V_{M, 0}+V_{M}}{V_{t o t, 0}+H F_{M K, 0} V_{M, 0}-V_{M}-n_{g p} \frac{F_{M K, 0}}{\gamma} V_{M, 0}}$

$e=\frac{n_{g p} \frac{F_{M K, 0}}{\gamma} e_{0}+\frac{V_{M}}{V_{S}}}{1+e_{0}+H F_{M K, 0} e_{0}-\frac{V_{M}}{V_{S}}-n_{g p} \frac{F_{M K, 0}}{\gamma} e_{0}}$

Since:

$\frac{V_{M}}{V_{S}}=\frac{V_{t o t}-V_{S}-V_{g p}}{V_{S}}$

Substituting (A6) In (A17) It results:

$\frac{V_{M}}{V_{S}}=\frac{V_{t o t, 0}+H F_{M K, 0} V_{M, 0}-V_{S}-V_{g p}}{V_{S}}$

Introducing (A3) in (A18) it results:

$\frac{V_{M}}{V_{S}}=\frac{V_{S}+V_{M, 0}+H F_{M K, 0} V_{M, 0}-V_{S^{-}}-\frac{F_{M K, 0}}{\gamma} V_{M, 0}}{V_{S}}=e_{0}+H F_{M K, 0} e_{0}-\frac{F_{M K, 0}}{\gamma} e_{0}$

Reintroducing equation (A19) In (A16), we have: 


$$
\begin{aligned}
& e=\frac{n_{g p} \frac{F_{M K, 0}}{\gamma} e_{0}+e_{0}+H F_{M K, 0} e_{0}-\frac{F_{M K, 0}}{\gamma} e_{0}}{1+e_{0}+H F_{M K, 0} e_{0}-e_{0}-H F_{M K, 0} e_{0}+\frac{F_{M K, 0}}{\gamma} e_{0}-n_{g p} \frac{F_{M K, 0}}{\gamma} e_{0}} \\
& e=\frac{e_{0}\left(n_{g p} \frac{F_{M K, 0}}{\gamma}+1+H F_{M K, 0}-\frac{F_{M K, 0}}{\gamma}\right)}{1+\frac{F_{M K, 0}}{\gamma} e_{0}-n_{g p} \frac{F_{M K, 0}}{\gamma} e_{0}}
\end{aligned}
$$

Thus:

$$
\begin{aligned}
\Delta e & =e_{0}-e \\
\Delta e & =e_{0}-\frac{e_{0}\left(n_{g p} \frac{F_{M K, 0}}{\gamma}+1+H F_{M K, 0}-\frac{F_{M K, 0}}{\gamma}\right)}{1+\frac{F_{M K, 0}}{\gamma} e_{0}-n_{g p} \frac{F_{M K, 0}}{\gamma} e_{0}} \\
\Delta e= & \frac{e_{0}+\frac{F_{M K, 0}}{\gamma} e_{0}^{2}-n_{g p} \frac{F_{M K, 0}}{\gamma} e_{0}^{2}-e_{0}\left(n_{g p} \frac{F_{M K, 0}}{\gamma}+1+H F_{M K, 0}-\frac{F_{M K, 0}}{\gamma}\right)}{1+\frac{F_{M K, 0}}{\gamma} e_{0}-n_{g p} \frac{F_{M K, 0}}{\gamma} e_{0}} \\
\Delta e= & \frac{e_{0}+\left(1-n_{g p}\right) \frac{F_{M K, 0}}{\gamma} e_{0}^{2}-n_{g p} \frac{F_{M K, 0}}{\gamma} e_{0}-e_{0}-H F_{M K, 0} e_{0}+\frac{F_{M K, 0}}{\gamma} e_{0}}{1+\frac{F_{M K, 0}}{\gamma} e_{0}-n_{g p} \frac{F_{M K, 0}}{\gamma} e_{0}} \\
\Delta e= & \frac{\left(1-n_{g p}-\gamma H+\left(1-n_{g p}\right) e_{0}\right) \frac{F_{M K, 0}}{\gamma} e_{0}}{1+\left(1-n_{g p}\right) \frac{F_{M K, 0}}{\gamma} e_{0}}
\end{aligned}
$$
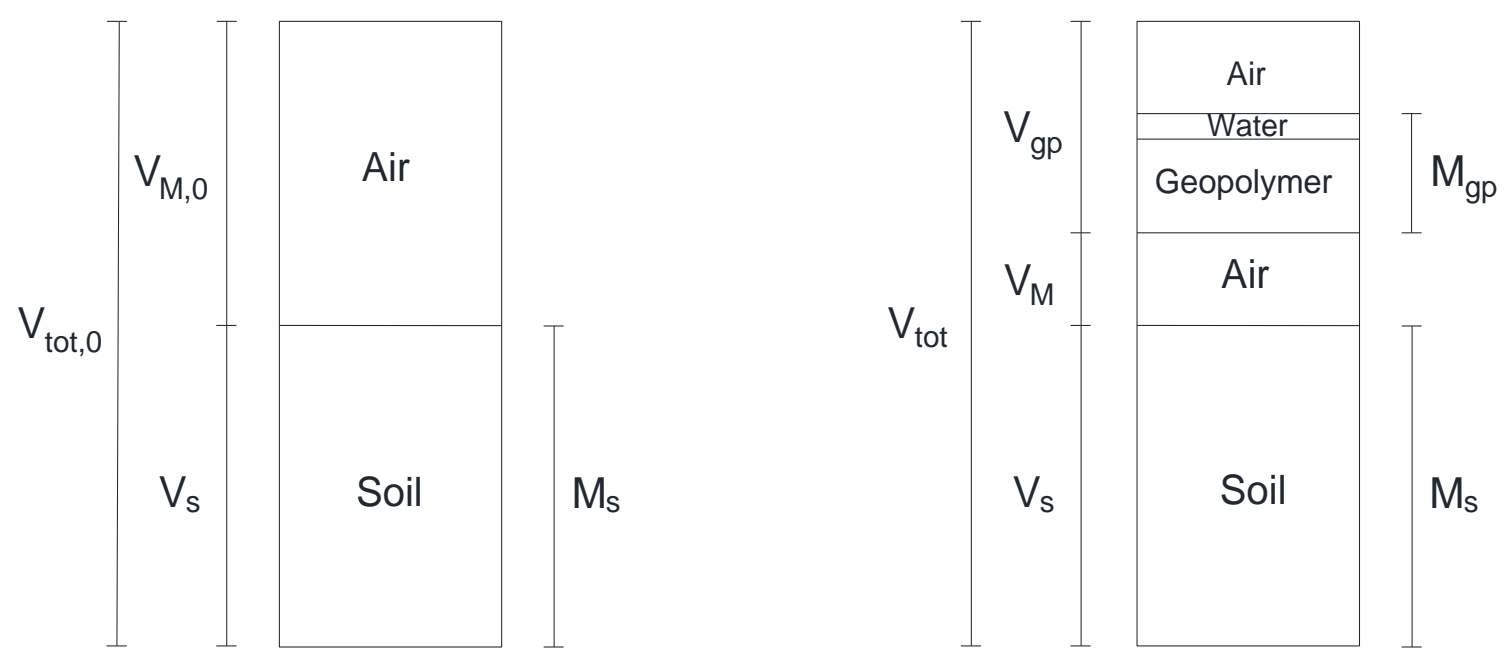

Figure A1 Sketch of the phase volumes involved in the sand treatment

\section{REFERENCES}

Abdullah, H. H., Shahin, M. A., Walske, M. L., Karrech A. (2020) Cyclic Behaviour of Clay Stabilised with Fly-ash Based Geopolymer Incorporating Ground Granulated 
Slag. Transportation Geotechnics (in press).

https://doi.org/10.1016/j.trgeo.2020.100430

Amaral, M. F., Da Fonseca, A. V., Arroyo, M., Cascante, G., \& Carvalho, J. (2011). Compression and shear wave propagation in cemented-sand specimens. Géotechnique Letters, 1(3), 79-84.

Arrigoni, A., Panesar, D.K., Duhamel, M., Opher, T., Saxel, S., Posen, I.D. \& MacLean, H.L. (2020). Life cycle greenhouse gas emissions of concrete containing supplementary cementitious materials: cut-off vs. substitution. Journal of Cleaner Production, 263, 121465, https://doi.org/10.1016/j.jclepro.2020.121465.

Arulrajah, A., Yaghoubi, M., Disfani, M. M., Horpibulsuk, S., Bo, M. W., \& Leong, M. (2018). Evaluation of fly ash-and slag-based geopolymers for the improvement of a soft marine clay by deep soil mixing. Soils and Foundations, 58(6), 1358-1370.

ASTM C597 (2016). Standard Test Method for Pulse Velocity Through Concrete. www.astm.org

ASTM D2216 (2019) Standard Test Methods for Laboratory Determination of Water (Moisture) Content of Soil and Rock by Mass. www.astm.org

ASTM 2166 (2016) Standard Test Method for Unconfined Compressive Strength of Cohesive Soil. www.astm.org

ASTM D4767 - 11 (2020) Standard Test Method for Consolidated Undrained Triaxial Compression Test for Cohesive Soils www.astm.org

ASTM D5084 (2016). Standard Test Methods for Measurement of Hydraulic Conductivity of Saturated Porous Materials Using a Flexible Wall Permeameter. www.astm.org ASTM D5856 (2015). Standard Test Method for Measurement of Hydraulic Conductivity of Porous Material Using a Rigid-Wall, Compaction-Mold Permeameter www.astm.org

ASTM D7263 (2018). Standard Test Method for Laboratory Determination of Density (Unit Weight) of Soil Specimens. www.astm.org 
BAUER Maschinen GmbH (2016). CSM Cutter Soil Mixing, https://www.bauer.de/export/shared/documents/pdf/bma/datenblatter/CSM Cutter Soil Mixing EN 905656 2.pdf905-656-2 EN.pdf (last accessed 07 October 2020).

Bellato, D., Spagnoli, G. \& Wiedenmann, U. (2015). Engineering and environmental aspects of offshore soil mixing. Proceedings of the Institution of Civil Engineers - Geotechnical Engineering, 168, No. 3, 267-278, https://doi.org/10.1680/geng.14.00044.

Bellato, D., Spagnoli, G. \& Simonini, P. (2020). Mineralogical and mechanical analysis of cement-stabilised sands. Proceedings of the Institution of Civil Engineers - Ground Improvement, 173, No. 1, 51-60, https://doi.org/10.1680/jgrim.18.00059

Bruce, M. E. C., Berg, R. R., Collin, J. G., Filz, G. M., Terashi, M., Yang, D. S., \& Geotechnica, S. (2013). Federal Highway Administration design manual: Deep mixing for embankment and foundation support (No. FHWA-HRT-13-046). United States. Federal Highway Administration. Offices of Research \& Development.

Cambefort, H. (1977). The principles and applications of grouting. Quarterly Journal of Engineering Geology and Hydrogeology, 10, 57-95, https://doi.org/10.1144/GSL.QJEG.1977.010.02.01.

Chapuis, R.P. \& Aubertin, M. (2003) On the use of the Kozeny-Carman's equation to predict the hydraulic conductivity of a soil. Canadian Geotechnical Journal 40, No. 3, $616-628$

Carman, P. C. (1937). Fluid flow through granular beds. Trans. Institution of Chemical Engineers 15, 150-166.

Chen, T., Sedighi, M., Jivkov, A.P. \& Seetharam, S. (2020). A model for hydraulic conductivity of compacted bentonite - inclusion of microstructure effects under confined wetting, Géotechnique (ahead of print), 1-14. Doi: 10.1680/jgeot.19.P.088

Christopher, B. R., Atmatzidis, D. K., \& Krizek, R. I. (1989). Laboratory testing of chemically grouted sand. Geotechnical Testing Journal, 12, No. 2, 109-118.

Consoli, N. C., Marques, S. F. V., Floss, M. F., \& Festugato, L. (2017). Broad-spectrum empirical correlation determining tensile and compressive strength of cement-bonded clean granular soils. Journal of Materials in Civil Engineering, 29(6), 06017004. 
Consoli, N. C., Fonseca, A. D., Silva, S. R., Cruz, R. C., \& Fonini, A. (2012). Parameters controlling stiffness and strength of artificially cemented soils. Géotechnique, 62(2), 177-183.

Consoli, N. C., Cruz, R. C., \& Floss, M. F. (2011). Variables controlling strength of artificially cemented sand: influence of curing time. Journal of Materials in Civil Engineering, 23(5), 692-696.

Consoli, N. C., Cruz, R. C., Floss, M. F., \& Festugato, L. (2010). Parameters controlling tensile and compressive strength of artificially cemented sand. Journal of Geotechnical and Geoenvironmental Engineering, 136(5), 759-763.

Cristelo, N., Glendinning, S. \& Pinto, A. T. 2011. Deep soft soil improvement by alkaline activation. Proceedings of the ICE-Ground Improvement, 164, No. 2, 73-82.

Cristelo, N., Glendinning, S., Fernandes, L. \& Pinto, A.T. (2013) Effects of alkalineactivated fly ash and Portland cement on soft soil stabilisation. Acta Geotechnica 8, 395-405. https://doi.org/10.1007/s11440-012-0200-9

Davidovits, J. (1994). Properties of geopolymer cements. $1^{\text {st }}$ International Conference on Alkaline Cements and Concretes. Kiev, Ukraine: Kiev State Technical University, 131-149.

Deng, Y., Yue, X., Liu, S., Chen, Y., \& Zhang, D. (2015). Hydraulic conductivity of cement-stabilized marine clay with metakaolin and its correlation with pore size distribution. Engineering Geology, 193, 146-152.

Doherty, P., Spagnoli, G., \& Bellato, D. (2016). Mixed-in-place response of two carbonate sands. Proceedings of the Institution of Civil Engineers - Geotechnical Engineering, 169 (2), 153-163, https://doi.org/10.1680/jgeen.15.00058.

Ghadir, P., \& Ranjbar, N. (2018) Clayey soil stabilisation using geopolymer and Portland cement. Construction and Building Materials, 188, 361-371.

Ghanbarian, B., Hunt, A. G., Ewing, R. P. \& Sahimi, M. (2013). Tortuosity in porous media: a critical review. Soil Sci. Soc. Am. J., 77, No. 5, 1461-1477.

Gluchovskij V.D. (1959) "Gruntosilikaty" Gosstrojizdat Kiev 1959. Patent USSR 245 627 (1967), Patent USSR 449894 (Patent appl. 1958, granted 1974). 
International Energy Agency (2018) Technology Roadmap: Low-Carbon Transition in the Cement Industry, IEA

Karstunen, M. (2014). Pre-study: Ground improvement for marginally stable slopes. Research Report 2014: Geotechnics-MK-1, Department of Civil and Environmental Engineering, Chalmers University of Technology (Sweden)

Kitazume, M. \& Terashi, M. (2013). The Deep-Mixing Method. Taylor \& Francis Group, London, UK

Kolovos, K.G., Asteris, P.G., Cotsovos, D.M., Badogiannis E., \& Tsivilis, S. (2013). Mechanical properties of soilcrete mixtures modified with metakaolin. Construction and Building Materials 47, 1026-1036.

Kozeny, J. (1927). Über kapillare Leitung des Wassers im Boden. R. Acad. Sci., Vienna, Proc. Class I 136, 271-306 (in German).

Kuenzel, C., Li, L., Vandeperre, L., Boccaccini, A. R., \& Cheeseman, C. R. (2014). Influence of sand on the mechanical properties of metakaolin geopolymers. Construction and Building Materials, 66, 442-446.

Kuenzel, C., Vandeperre, L. J., Donatello, S., Boccaccini, A. R., \& Cheeseman, C. (2012). Ambient temperature drying shrinkage and cracking in metakaolin-based geopolymers. Journal of the American Ceramic Society, 95(10), 3270-3277.

Larsson, S. (2003) Mixing processes for ground improvement by deep mixing. PhD Thesis, Royal Institute of Technology, Stockholm.

Le Kouby, A., Guimond-Barrett, A., Reiffsteck, P., \& Pantet, A. (2018). Influence of drying on the stiffness and strength of cement-stabilized soils. Geotechnical and Geological Engineering, 36(3), 1463-1474.

Liu, Z., Cai, C.S., Liu, F., \& Fan, F. (2016). Feasibility study of loess stabilisation with fly ash-based geopolymer. Journal of Materials in Civil Engineering, 28, No. 5, 04016003, https://doi.org/10.1061/(ASCE)MT.1943-5533.0001490.

Mosadegh, A., Szymkiewicz, F., \& Nikraz, H. (2017). An experimental investigation of the impact of specimen preparation and curing conditions on cement-treated material strength (deep mixing method). Australian Journal of Civil Engineering, 15(1), 49-60. 
Murmu, A.L., Jain, A. \& Patel, A. (2019) Mechanical properties of alkali activated fly ash geopolymer stabilised expansive clay. KSCE Journal of Civil Engineering, 23, No. 9, 3875-3888, DOI 10.1007/s12205-019-2251-z.

Nguyen, T.T. \& Indraratna, B. (2020). Role of particle shape on hydraulic conductivity of granular soils captured through Kozeny-Carman approach. Géotechnique Letters, 10, No. 3, 1-6. Doi : 10.1680/jgele.20.00032.

Panesar, D.K. (2019). Supplementary cementing materials. In Developments in the Formulation and Reinforcement of Concrete, 55-85, Mindess S. (ed), Elsevier B.V.

Provis, J.L. \& Bernal. S.A. (2014). Geopolymers and related alkali-activated materials. Annual Review of Materials Research 44, 299-327. https://doi.org/10.1146/annurevmatsci-070813-113515.

Puppala, A.J., Madhyannapu, R.S., \& Nazarian, S. (2008). Special Specification for Deep Soil Mixing. Product 0-5179-P1, Project 0-5179, The University of Texas at Arlington, Texas.

Rios, S., Cristelo, N., Viana Da Fonseca, A \& Ferreira, C. (2016). Structural performance of alkali-activated soil ash versus soil cement. Journal of Materials in Civil Engineering, 28, No. 2, https://doi.org/10.1061/(ASCE)MT.1943-5533.0001398

Rios, S., Ramos, C., Viana Da Fonseca, A., Cruz, N., \& Rodrigues, C. (2017). Mechanical and durability properties of a soil stabilised with an alkali-activated cement. European Journal of Environmental and Civil Engineering, 23, No. 2, 245-267.

Romero, E. (2013) A microstructural insight into compacted clayey soils and their hydraulic properties. Engineering Geology, 165, 3-19, https://doi.org/10.1016/j.enggeo.2013.05.024.

Romero, E., Gens, A. \& Lloret, A. (1999) Water permeability, water retention and microstructure of unsaturated compacted Boom clay. Engineering Geology 54, 117-27.

Romero, E. \& Simms, P.H. (2008). Microstructure investigation in unsaturated soils: a review with special attention to contribution of mercury intrusion porosimetry and environmental scanning electron microscopy. Geotechnical and Geological Engineering 26, No. 6, 705-727 
Rong-rong, Z. \& Dong-dong, M. (2020). Effects of Curing Time on the Mechanical Property and Microstructure Characteristics of Metakaolin-Based Geopolymer Cement-Stabilized Silty Clay. Advances in Materials Science and Engineering, D 9605941, https://doi.org/10.1155/2020/9605941.

Rutherford, C., Biscontin, G., \& Briaud, J. L. (2005). Design manual for excavation support using deep mixing technology, Texas A\&M University

Sargent, P., Hughes, P. N., Rouainia, M. \& White, M. L. 2013. The use of alkali activated waste binders in enhancing the mechanical properties and durability of soft alluvial soils, Engineering Geology, 152, 96-108.

Spagnoli, G., Doherty, P., Bellato, D. \& Weixler L. (2014). Latest technological developments in offshore deep mixing for piled oil and gas platforms. ASME 2014 33rd International Conference on Ocean, Offshore and Arctic Engineering, June 8-13, 2014, OMAE2014-23045, V003T10A001, https://doi.org/10.1115/OMAE2014-23045, San Francisco, California, USA.

Singhi, B., Laskar, A.I., \& Ali Ahmed, M. (2017) Mechanical behavior and sulfate resistance of alkali activated stabilised clayey soil. Geotechnical and Geological Engineering 35, No. 5, 1907-1920.

Singhi, B., Laskar, A.I., \&Ali Ahmed, M. (2016) Investigation on soil-geopolymer with slag, fly ash and their blending. Arabian Journal for Science and Engineering 41, $393-$ 400, DOI 10.1007/s13369-015-1677-y.

Spagnoli, G., Seidl, W., Romero, E., Arroyo, M., Gómez, R., \& López J. (2020). Unconfined compression strength of sand-fines mixtures treated with chemical grouts. Proceedings of 10th International Symposium on Geotechnical Aspects of Underground Construction ins Soft Ground (in press).

Terashi, M., Tanaka, H., Mitsumoto, T., Honma, S., \& Ohhashi, T. (1983) Fundamental properties of lime and cement treated soils (3rd Report). Report of the Port and Harbour Research Institute, Vol. 22. No. 1. pp. 69-96 (in Japanese).

Terzaghi, K., Peck, R., Mesri, G. (1996). Soil Mechanics in Engineering Practice. John Wiley \& Sons 
Topolnicki, M. (2012) In-situ soil mixing. Ground Improvement, ed. by Klaus Kirsch, Alan Bell, CRC Press, Boca Raton, 329-433.

Velosa, A.L., Rocha, F. \& Veiga, R. (2009). Influence of chemical and mineralogical composition of metakaolin on mortar characteristics. Acta Geodynamica et Geomaterialia, Vol. 6, No. 1, 121-126.

Verdolotti, L., lannace, S., Lavorgna, M. \& Lamanna R (2008). Geopolymerization reaction to consolidate incoherent pozzolanic soil. Journal of Materials Science 43, 865873. https://doi.org/10.1007/s10853-007-2201-x

Wu, Z., Deng, Y., Liu, S., Liu, Q., Chen, Y., \& Zha, F. (2016). Strength and microstructure evolution of compacted soils modified by admixtures of cement and metakaolin. Applied Clay Science, 127, 44-51.

Yip, C. K., Lukey, G. C., \& van Deventer, J. S. J. (2005). The coexistence of geopolymeric gel and calcium silicate hydrate at the early stage of alkaline activation. Cement and Concrete Research, 35, 1688-1697.

Zhang, M., Guo, H., El-Korchi, T., Zhang, G., \& Tao, M. (2013) Experimental feasibility study of geopolymer as the next-generation soil stabiliser. Construction and Building Materials 47, 1468-1478. 
TABLES

Table 1 Physical and chemical properties of the base materials

\begin{tabular}{|c|c|c|c|c|}
\hline & $\begin{array}{l}\text { Holcim } \\
\text { sand }\end{array}$ & Carbonate silt & $\begin{array}{l}\text { Sand with } 10 \% \\
\text { carbonate silt }\end{array}$ & $\begin{array}{c}\text { metakaolin } \\
\text { powder }\end{array}$ \\
\hline $\mathrm{SiO}_{2}$ content $(\%)$ & 92.1 & - & 82.9 & 55 \\
\hline $\mathrm{CaCO}_{3}$ content (\%) & & 98.2 & 9.8 & \\
\hline $\mathrm{pH}$ value & 6.69 & 9.90 & & 6 \\
\hline Maximum grain size, $d_{100}(\mathrm{~mm})$ & 0.710 & 0.161 & 0.710 & $0.080^{\star * *}$ \\
\hline Mean grain size, $d_{50}(\mathrm{~mm})$ & 0.450 & 0.033 & 0.450 & $0.010-0.015$ \\
\hline Grain size, $d_{10}(\mathrm{~mm})$ & 0.336 & 0.003 & 0.172 & - \\
\hline$<2 \mu \mathrm{m}(\%)$ & - & 8.0 & 0.8 & 100 \\
\hline Modal grain size, $d_{\text {mode }}(\mathrm{mm})$ & 0.400 & 0.124 & 0.400 & 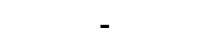 \\
\hline Coefficient of uniformity, $C_{u}$ & 1.42 & 15.3 & 1.92 & - \\
\hline Density of solids, $\rho_{s}\left(\mathrm{Mg} / \mathrm{m}^{3}\right)$ & 2.65 & 2.71 & 2.66 & 2.40 \\
\hline Hygroscopic w/c (\%) at $\mathrm{RH}=50 \%$ & $<0.3$ & 0.1 & $<0.3$ & - \\
\hline Bulk density as poured $\left(\mathrm{Mg} / \mathrm{m}^{3}\right)$ & 1.34 & 1.10 & 1.47 & - \\
\hline Void ratio as poured & 0.825 & 0.464 & 0.584 & \\
\hline $\begin{array}{l}\text { Hydraulic conductivity as poured, } \\
k_{w}(\mathrm{~m} / \mathrm{s})\end{array}$ & $7.67 \times 10^{-4}$ & - & $2.85 \times 10^{-4}$ & \\
\hline Maximum void ratio, $e_{\max }$ & 0.982 & - & - & - \\
\hline Minimum void ratio, $e_{\min }$ & 0.532 & - & - & - \\
\hline Dominant mode pore size* & $\begin{array}{l}0.124 \\
e=0.703\end{array}$ at & - & $\begin{array}{l}0.170 \\
e=0.679\end{array}$ & - \\
\hline Specific surface, $S_{S}\left(\mathrm{~m}^{2} / \mathrm{g}\right)$ & $0.009^{*}$ & - & $0.012^{*}$ & $17^{\star *}$ \\
\hline
\end{tabular}

Table 2 Overview of the experimental program

\begin{tabular}{|c|c|c|c|c|c|c|c|c|c|}
\hline \multicolumn{7}{|c|}{} & \multicolumn{7}{|c|}{ TEST PERFORMED } \\
\hline $\begin{array}{c}\text { MATE- } \\
\text { RIAL }\end{array}$ & $F_{M K, 0}(\%)$ & CURING & $\begin{array}{c}\text { Permea- } \\
\text { bility }\end{array}$ & UCS & Bar wave & MIP & FESEM & $\begin{array}{c}\text { X-RAY } \\
\text { SCAN }\end{array}$ & $\begin{array}{c}\text { Paraffin Bulk den- } \\
\text { sity }\end{array}$ \\
\hline S & 0 & na & $\mathrm{x}$ & na & na & $\mathrm{x}$ & $\mathrm{x}$ & $\mathrm{x}$ & na \\
\hline SO & 0 & na & $\mathrm{x}$ & na & na & $\mathrm{x}$ & $\mathrm{x}$ & - & na \\
\hline MK & na & D & $\mathrm{x}$ & $\mathrm{x}$ & $\mathrm{x}$ & $\mathrm{x}$ & - & $\mathrm{x}$ & $\mathrm{x}$ \\
\hline MK & na & W & - & $\mathrm{x}$ & $\mathrm{x}$ & $\mathrm{x}$ & - & - & $\mathrm{x}$ \\
\hline SMK & 100 & $\mathrm{D}$ & $\mathrm{x}$ & $\mathrm{x}$ & $\mathrm{x}$ & $\mathrm{x}$ & $\mathrm{x}$ & $\mathrm{x}$ & $\mathrm{x}$ \\
\hline SOMK & 100 & $\mathrm{D}$ & $\mathrm{x}$ & $\mathrm{x}$ & - & $\mathrm{x}$ & $\mathrm{x}$ & $\mathrm{x}$ & $\mathrm{x}$ \\
\hline SMK & 100 & $\mathrm{~W}$ & - & $\mathrm{x}$ & $\mathrm{x}$ & $\mathrm{x}$ & - & - & $\mathrm{x}$ \\
\hline SMK & 40 & $\mathrm{D}$ & $\mathrm{x}$ & - & - & - & - & $\mathrm{x}$ & - \\
\hline SOMK & 40 & $\mathrm{D}$ & $\mathrm{x}$ & - & - & - & - & - & - \\
\hline
\end{tabular}


Table 3 Material proportions in the mixtures

\begin{tabular}{|l|l|l|l|l|l|}
\hline Size & Soil & $F_{M K, 0}$ & Dry MK /dry soil & Dry MK/total solid & Slurry/soil \\
\hline & & $\%$ & $\mathrm{w} / \mathrm{w}$ & $\mathrm{w} / \mathrm{w}$ & $\mathrm{w} / \mathrm{w}$ \\
\hline TX & $\mathrm{S}$ & 100 & $12.9 \%$ & $11.4 \%$ & $38.6 \%$ \\
\hline UC & $\mathrm{S}$ & 100 & $13.3 \%$ & $11.7 \%$ & $39.9 \%$ \\
\hline TX & SO & 100 & $10.1 \%$ & $9.1 \%$ & $30.2 \%$ \\
\hline UC & SO & 100 & $10.5 \%$ & $9.5 \%$ & $31.4 \%$ \\
\hline TX & S & 40 & $5.2 \%$ & $4.9 \%$ & $15.5 \%$ \\
\hline TX & SO & 40 & $4.0 \%$ & $3.9 \%$ & $12.0 \%$ \\
\hline
\end{tabular}


Table 4 TX specimens: results from MIP and permeability values.

\begin{tabular}{|c|c|c|c|c|c|c|c|c|c|c|c|}
\hline Specimen & $\begin{array}{l}e_{m} \\
(-)\end{array}$ & $\begin{array}{l}\text { eM } \\
(-)\end{array}$ & $X_{m, \text { peak }}(\mu \mathrm{m})$ & $\mathrm{X}_{\mathrm{M}, \text { peak }}(\mu \mathrm{m})$ & $\begin{array}{l}e^{*} \\
(-)\end{array}$ & $\mathrm{n}(-)$ & $\mathrm{n}_{\mathrm{gp}}(-)$ & $F_{M K}(-)$ & $S_{S}\left(\mathrm{~m}^{2} / \mathrm{g}\right)$ & $\begin{array}{l}\rho_{\mathrm{s}} \\
\left(\mathrm{Mg} / \mathrm{m}^{3}\right)\end{array}$ & $\mathrm{k}_{\mathrm{w}}(\mathrm{m} / \mathrm{s})$ \\
\hline $\mathrm{S}$ & - & 0.676 & - & 127 & 0.676 & 0.403 & - & 0.00 & 0.010 & 2.65 & $7.67 e-04$ \\
\hline SO & - & 0.435 & - & 173 & 0.435 & 0.303 & - & 0.00 & 0.012 & 2.65 & $2.85 e-04$ \\
\hline MKD3 & 0.691 & 0.002 & 0.020 & - & 0.693 & 0.409 & - & 1.00 & 57.870 & 2.05 & - \\
\hline MKD7 & 1.079 & 0.015 & 0.026 & - & 1.094 & 0.522 & - & 1.00 & 74.610 & 2.40 & $7.20 \mathrm{e}-09$ \\
\hline MKD28 & 1.318 & 0.034 & 0.027 & - & 1.352 & 0.575 & 0.575 & 1.00 & 87.480 & 2.40 & $4.60 e-09$ \\
\hline MKW7 & 0.825 & 0.010 & 0.019 & - & 0.835 & 0.455 & - & 1.00 & 54.360 & 2.40 & - \\
\hline MKW28 & 0.902 & 0.020 & 0.019 & - & 0.922 & 0.480 & - & 1.00 & 62.820 & 2.40 & - \\
\hline SMK(100)D3 & 0.314 & 0.133 & 0.019 & 20 & 0.447 & 0.309 & - & 0.66 & 19.980 & 2.59 & $9.80 e-09$ \\
\hline SMK(100)D7 & - & - & - & - & 0.450 & 0.310 & - & 0.65 & $19.125^{\star *}$ & 2.59 & - \\
\hline SMK(100)D28 & 0.261 & 0.164 & 0.024 & 20 & 0.425 & 0.298 & 0.207 & 0.62 & 16.760 & 2.59 & $2.00 e-07$ \\
\hline SMK(100)W28 & 0.360 & 0.103 & 0.018 & 8 & 0.463 & 0.316 & - & 0.69 & 20.240 & 2.59 & - \\
\hline SOMK(100)D3 & 0.203 & 0.199 & 0.027 & 27 & 0.402 & 0.287 & - & 0.56 & 13.710 & 2.58 & $1.10 \mathrm{e}-08$ \\
\hline SOMK(100)D7 & - & - & - & - & 0.474 & 0.322 & - & 0.49 & $8.796^{* *}$ & 2.58 & $4.60 e-08$ \\
\hline SOMK(100)D28 & 0.260 & 0.229 & 0.027 & 31 & 0.489 & 0.328 & 0.206 & 0.53 & 17.470 & 2.58 & $1.50 \mathrm{e}-07$ \\
\hline SMK(40)D3 & - & - & - & - & 0.628 & 0.386 & - & 0.34 & $3.172^{* *}$ & 2.61 & $2.00 \mathrm{e}-06$ \\
\hline SMK(40)D7 & - & - & - & - & 0.608 & 0.378 & - & 0.32 & $2.684^{* *}$ & 2.61 & $1.21 \mathrm{e}-06$ \\
\hline SMK(40)D28 & - & - & - & - & 0.625 & 0.385 & - & 0.25 & $1.362^{* *}$ & 2.61 & $9.65 e-07$ \\
\hline SOMK(40)D3 & - & - & - & - & 0.565 & 0.361 & - & 0.34 & $3.148^{\star *}$ & 2.63 & $1.01 \mathrm{e}-06$ \\
\hline SOMK(40)D7 & - & - & - & - & 0.566 & 0.361 & - & 0.27 & $1.669^{* *}$ & 2.63 & $2.10 \mathrm{e}-07$ \\
\hline SOMK(40)D28 & - & - & - & - & 0.568 & 0.362 & - & 0.21 & $0.835^{* *}$ & 2.64 & $4.75 e-07$ \\
\hline
\end{tabular}

${ }^{*}$ estimated from $F_{M K}$, ${ }^{*}$ total intruded MIP value, when available. Otherwise from dry density and solids weight. 
Table 5 UC specimens: strength and stiffness measurements

\begin{tabular}{|c|c|c|c|c|c|c|c|c|c|c|c|}
\hline \multirow[b]{2}{*}{ Specimen } & \multirow{2}{*}{$\begin{array}{c}\text { eo (soil, } \\
\text { as } \\
\text { poured) } \\
(-)\end{array}$} & \multirow[b]{2}{*}{$F_{M K}(-)$} & \multirow[b]{2}{*}{$\eta(-)$} & \multirow[b]{2}{*}{$\mathrm{C}_{\mathrm{iv}}(-)$} & \multirow[b]{2}{*}{$\begin{array}{c}\mathrm{qu} \\
(\mathrm{MPa})\end{array}$} & \multirow[b]{2}{*}{$\mathrm{E}_{0}(\mathrm{GPa})$ * } & \multicolumn{4}{|c|}{$\mathrm{E}_{\mathrm{sec}}(\mathrm{GPa})$} & \multirow[b]{2}{*}{$\begin{array}{c}E_{\text {sec } 50} / \\
q_{u}\end{array}$} \\
\hline & & & & & & & $\begin{array}{l}\varepsilon_{1} \\
0.01 \%\end{array}$ & $\begin{array}{l}\varepsilon_{1} \\
0.05 \%\end{array}$ & $\begin{array}{l}\varepsilon_{1} \\
0.1 \%\end{array}$ & $\begin{array}{l}E_{\text {sec50 }} \\
\left(50 \% q_{u}\right)\end{array}$ & \\
\hline MKW7 & - & 1 & - & - & 1.440 & 2.205 & 2.607 & 0.58 & 0.34 & 0.172 & 119.4 \\
\hline MKW14 & - & 1 & - & - & 1.430 & 3.643 & 3.670 & 0.814 & 0.474 & 0.248 & 173.4 \\
\hline MKW28 & - & 1 & - & - & 1.180 & 3.919 & 4.400 & 0.984 & 0.563 & 0.474 & 401.7 \\
\hline MKD7 & - & 1 & - & - & $1.320^{b}$ & 0.491 & - & 1.015 & 0.553 & 0.285 & 216.0 \\
\hline MKD7 & - & 1 & - & - & $1.690^{b}$ & 0.491 & - & 0.955 & 0.515 & 0.157 & 92.9 \\
\hline MKD14 & - & 1 & - & - & $0.640^{\mathrm{b}}$ & 0.878 & 0.543 & 0.132 & 0.073 & 0.029 & 45.3 \\
\hline SMK(100)D3 & 0.876 & 0.68 & 0.410 & 0.090 & 1.440 & - & 3.800 & 0.86 & 0.518 & 0.348 & 241.7 \\
\hline SMK(100)D3 R & 0.852 & 0.79 & 0.410 & 0.090 & 2.070 & - & 2.725 & 0.70 & 0.455 & 0.292 & 141.1 \\
\hline SMK(100)D7 & 0.847 & 0.59 & 0.410 & 0.090 & 1.180 & 0.587 & 1.425 & 0.38 & 0.265 & 0.189 & 160.2 \\
\hline SMK(100)D28 & 0.854 & 0.58 & 0.410 & 0.090 & 1.100 & 0.707 & 1.475 & 0.393 & 0.267 & 0.190 & 172.7 \\
\hline SMK(100)W7 & 0.852 & 0.78 & 0.410 & 0.090 & 2.05 & 3.444 & 3.580 & 0.854 & 0.542 & 0.349 & 170.2 \\
\hline SMK(100)W7 R & 0.852 & 0.77 & 0.410 & 0.090 & 1.99 & 3.444 & 5.320 & 1.146 & 0.673 & 0.390 & 196.0 \\
\hline SMK(100)W14 & 0.852 & 0.78 & 0.410 & 0.090 & 1.700 & 4.151 & 2.945 & 0.703 & 0.442 & 0.289 & 170.0 \\
\hline SMK(100)W28 & 0.852 & 0.79 & 0.410 & 0.090 & 1.510 & 5.401 & 3.890 & 0.88 & 0.524 & 0.335 & 221.9 \\
\hline SOMK(100)D3 & 0.789 & 0.73 & 0.332 & 0.063 & 1.760 & - & 3.366 & 0.735 & 0.44 & 0.222 & 126.1 \\
\hline SOMK(100)D7 & 0.811 & 0.62 & 0.332 & 0.063 & 1.400 & - & 7.267 & 1.496 & 0.805 & - & - \\
\hline SOMK(100)D28 & 0.789 & 0.62 & 0.332 & 0.063 & 1.780 & - & 7.265 & 1.565 & 0.867 & 0.800 & 449.4 \\
\hline
\end{tabular}

b Values corrected with ASTM D2938-79 for samples with $\mathrm{H} / \mathrm{D}<2$

\section{R Repeated test}

* calculated through ultrasonic wave velocity method, averaging 4 lectures of wave's travel time. 


\section{FIGURES}

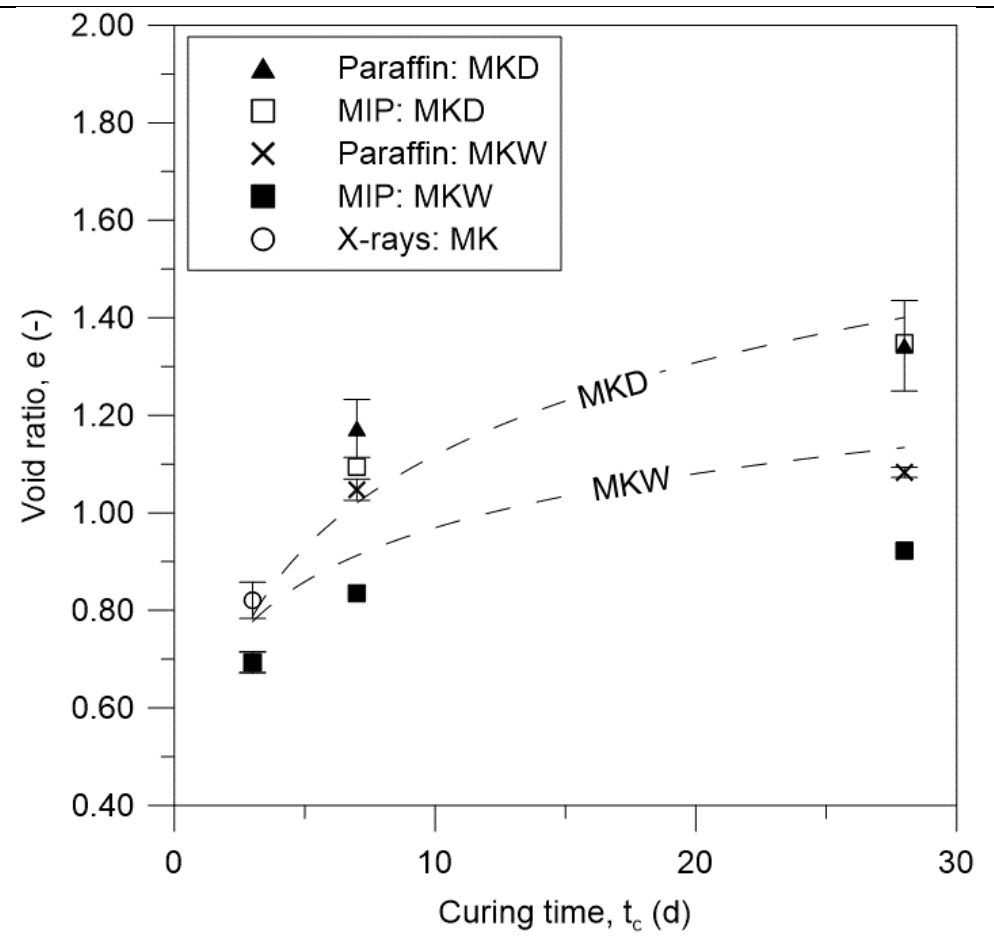

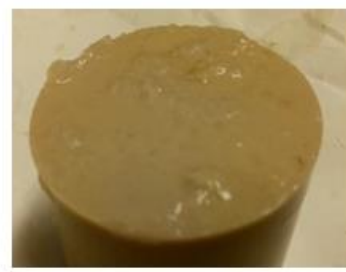

(b)

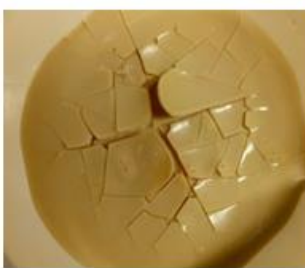

(c)

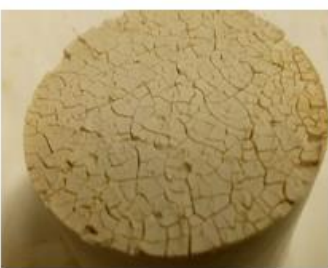

(d)

Figure 1a) evolution of the void ratio of metakaolin geopolymer cured dry (MKD) and wet (MKW). Samples of MKD for paraffin tests at: 3 days (b), 7 days (c) and 28 days (d). 


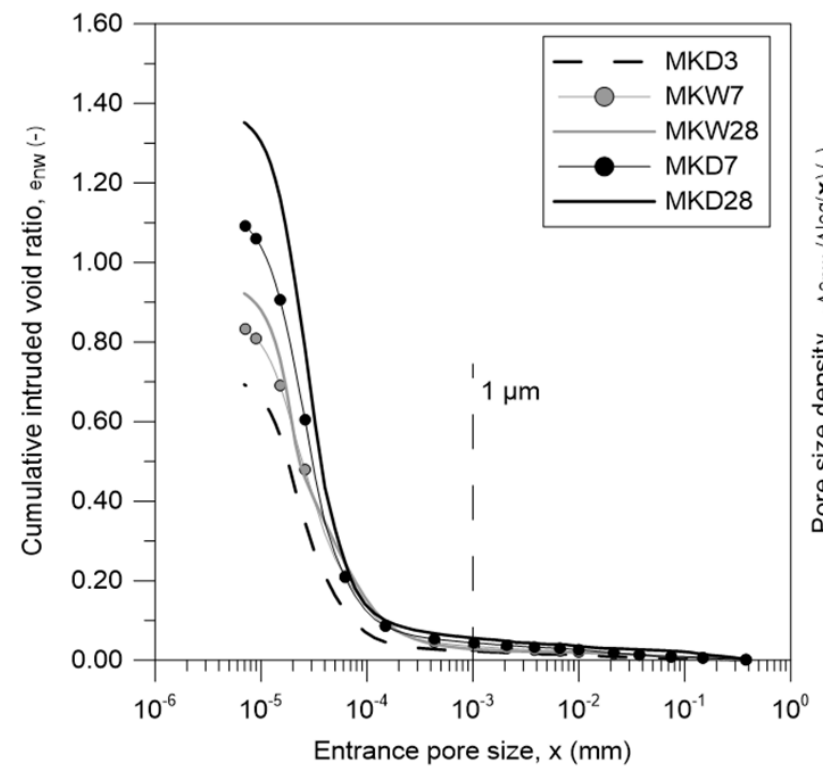

(a)

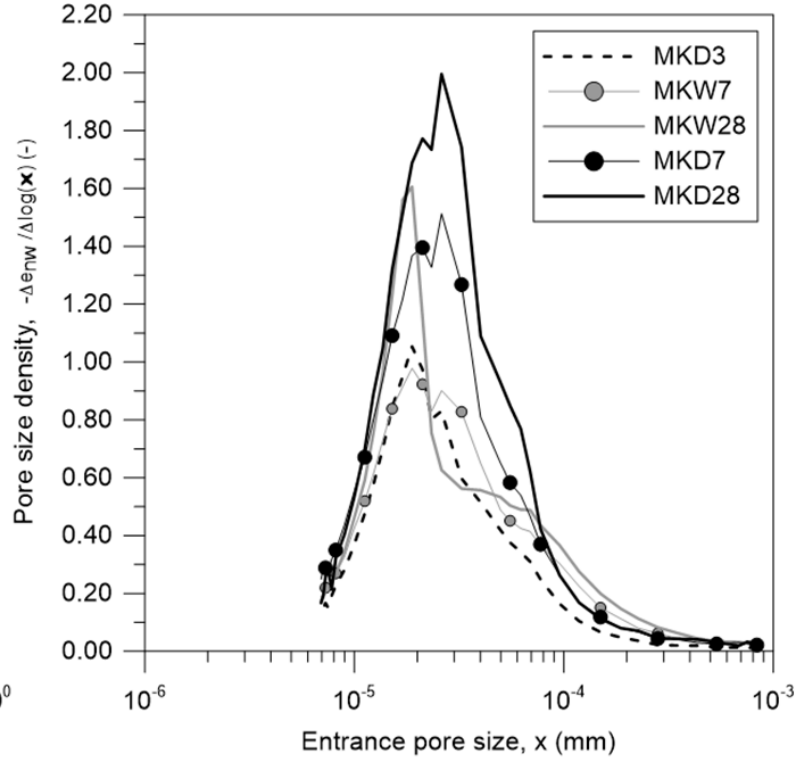

(b)

Figure 2 Cumulative (a) and differential (b) pore size distribution of metakaolin geopolymer cured dry (MKD) and wet (MKW).

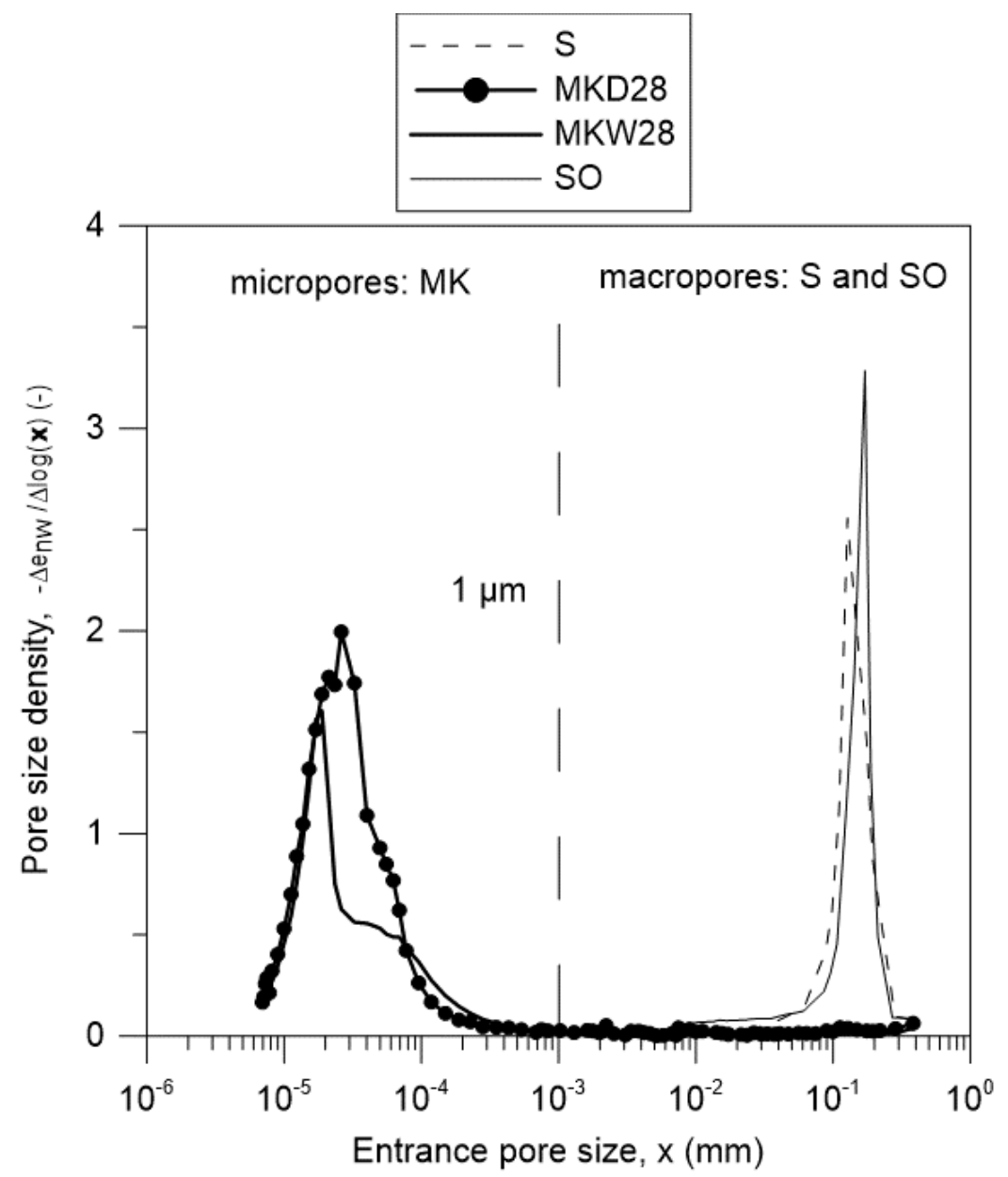

Figure 3 Pore size density functions for cured metakaolin geopolymer (MKD28, MKW28) and soils (S, SO). 


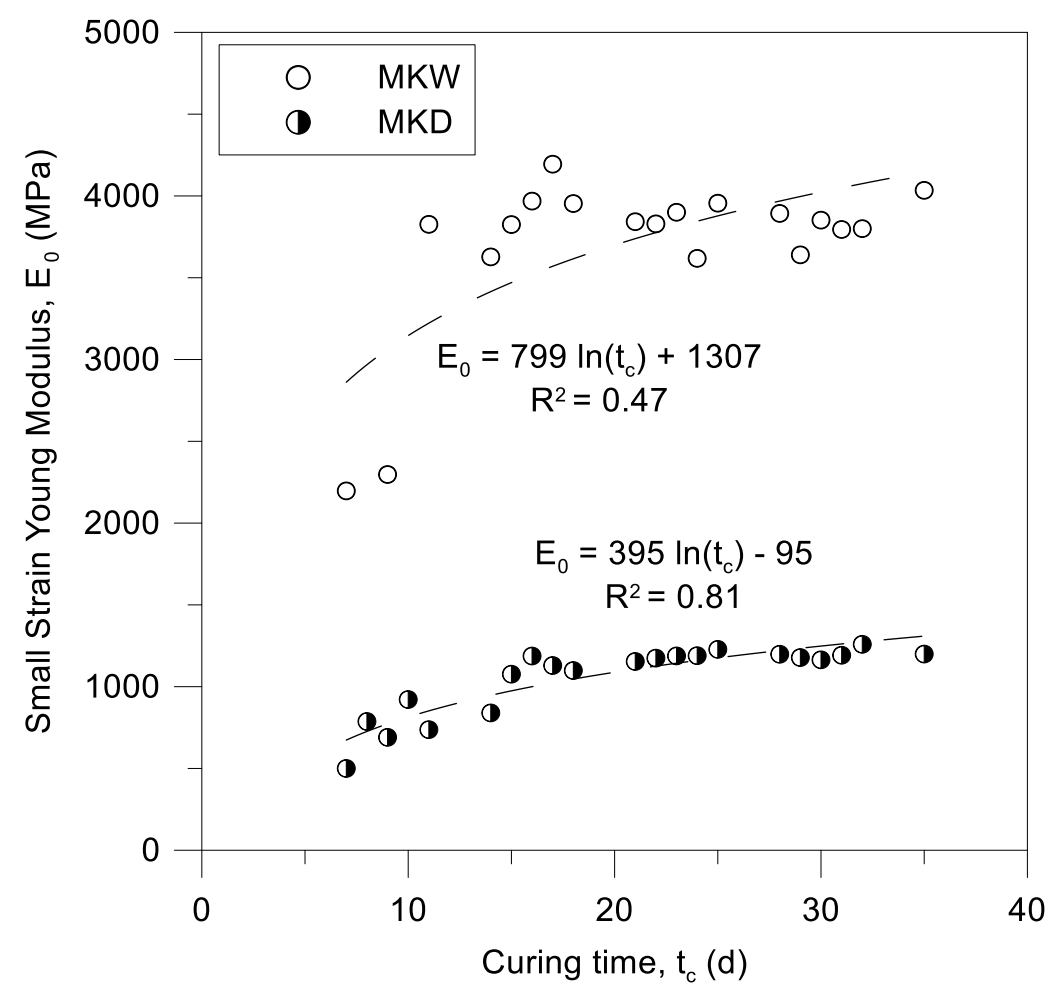

Figure 4 Evolution of the Young Modulus in MKD and MKW (UItrasonic Pulse Velocity Tester).

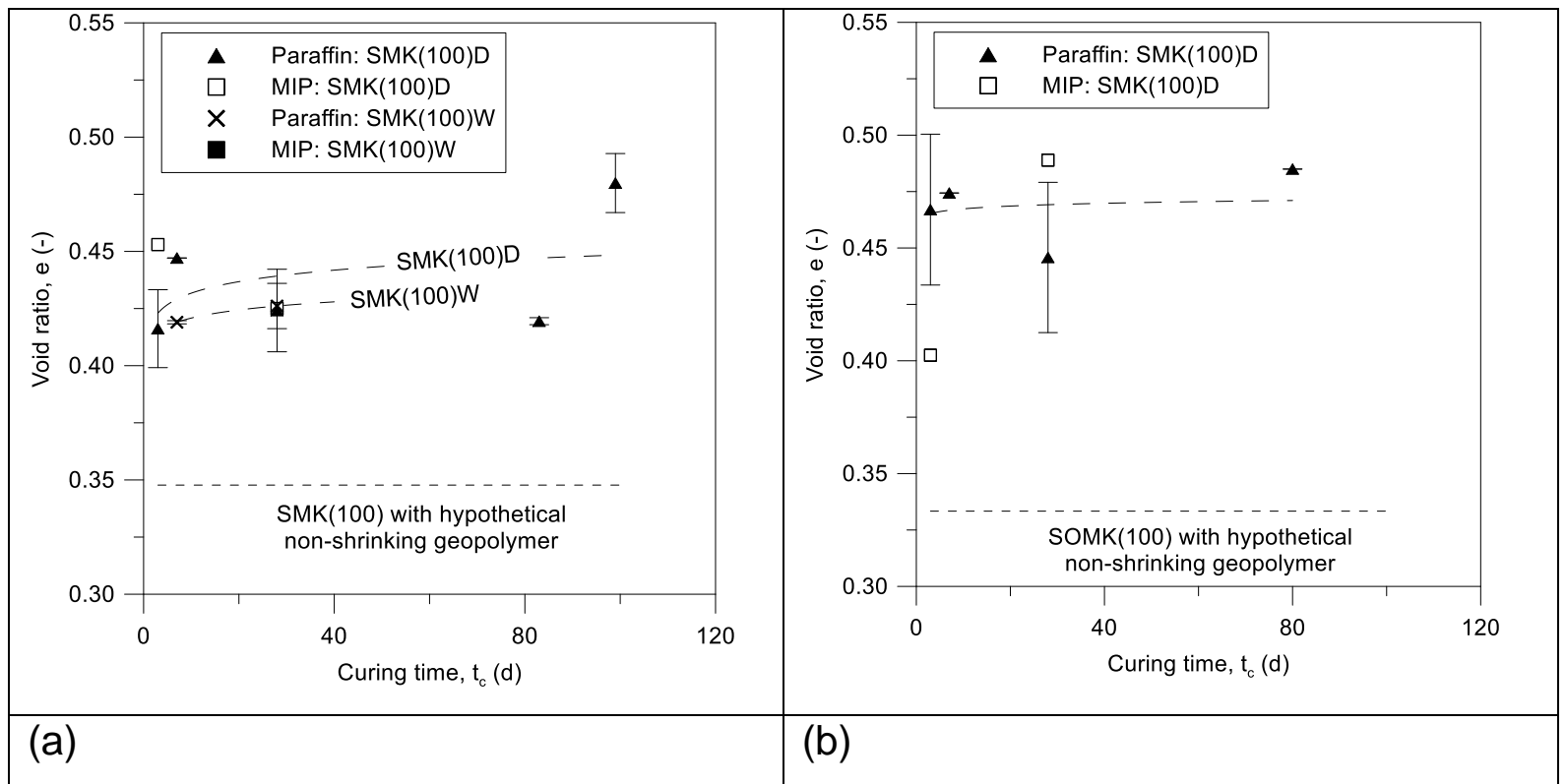

Figure 5 Evolution of void ratio with time in: SMK(100)D and SMK(100)W (a) and $\operatorname{SOMK}(100) D(b)$. 


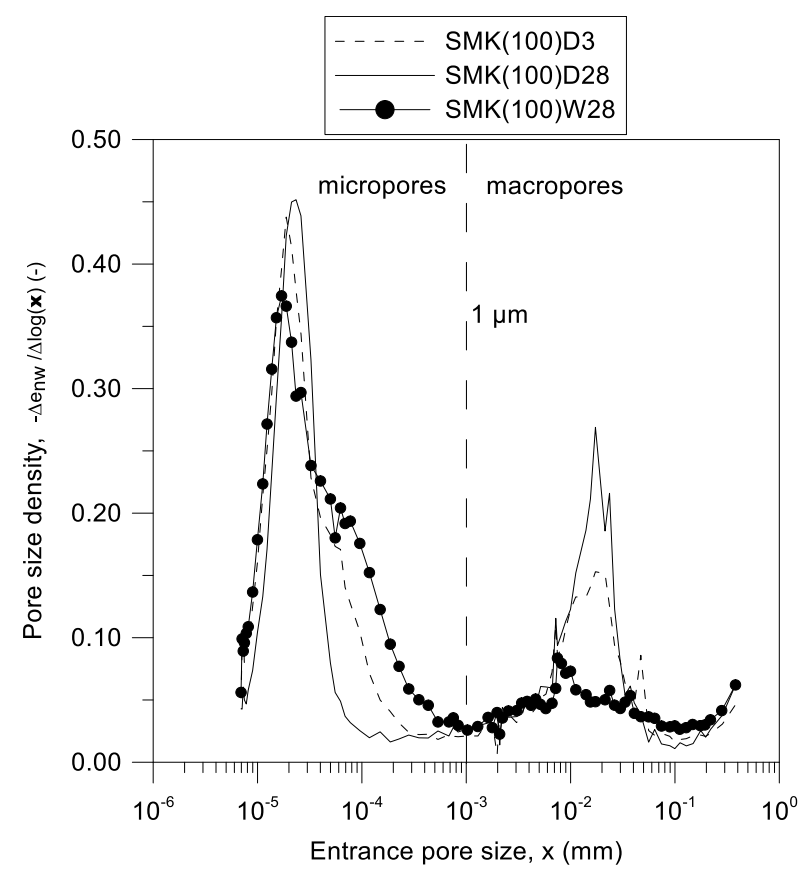

Figure 6 Effect of curing conditions on differential pore size distribution of SMK(100).

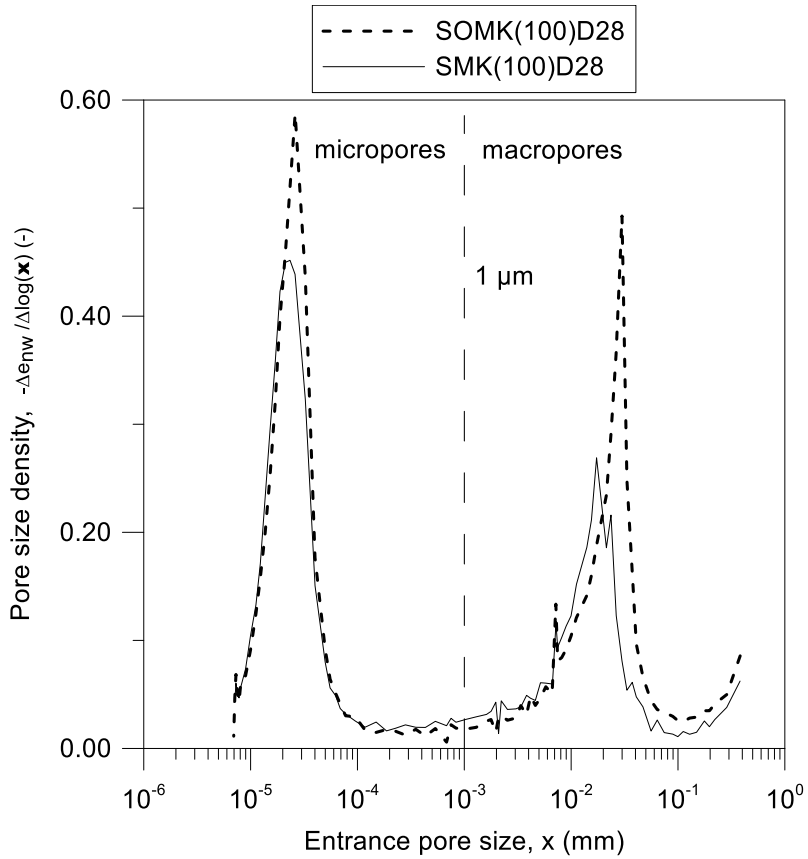

Figure 7 Comparison of SMK(100)D28 and SOMK(100)D28. 


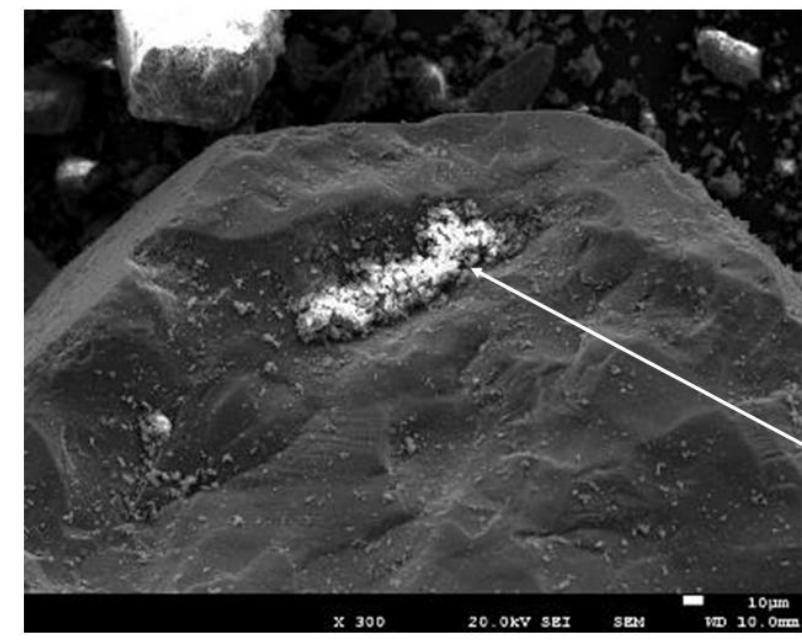

(a)

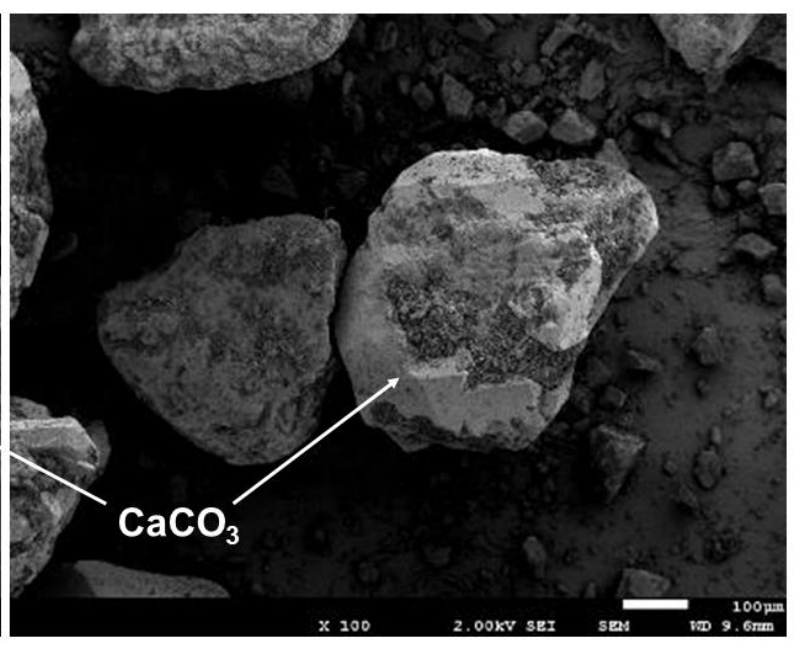

(b)

Figure 8 FESEM images of SO at different magnifications: sand grain partially (a) and fully (b) covered by $\mathrm{CaCO}_{3}$.

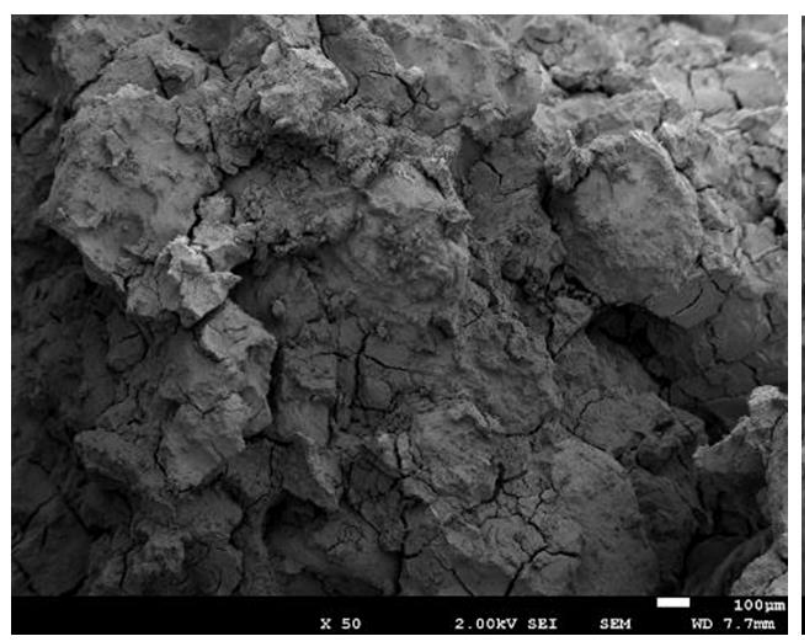

(a)

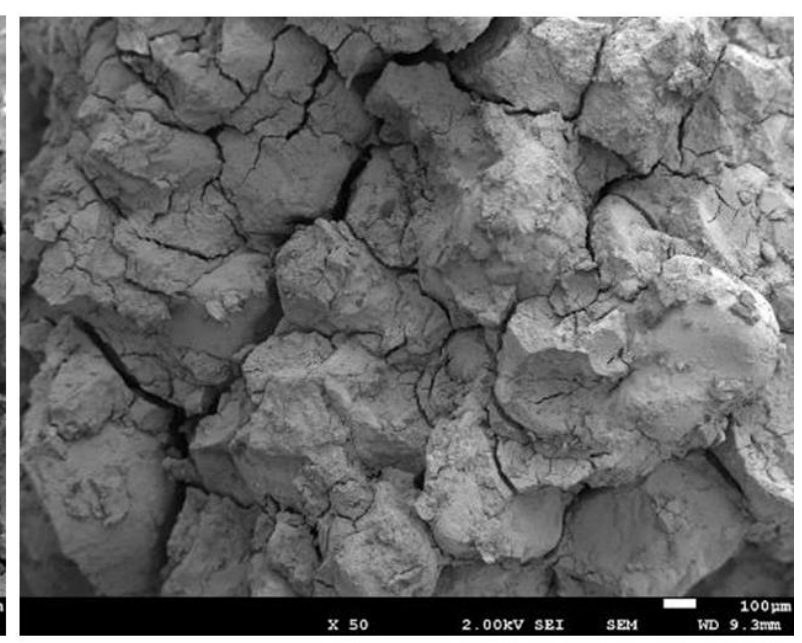

(b)

Figure 9 FESEM images at the same magnification on: a) SMK(100)D28 and b) SOMK(100)D28. 


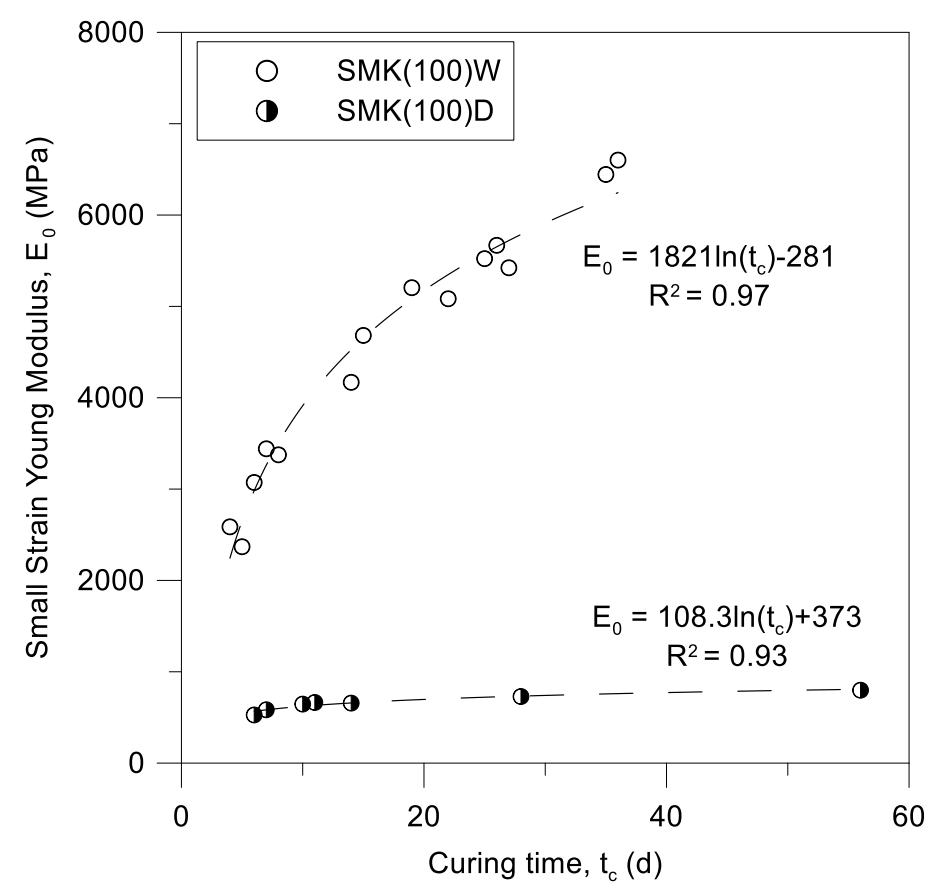

Figure 10 Evolution of the Young Modulus in SMK(100)D and SMK(100)W. Measurements with Ultrasonic Pulse Velocity Tester.

0 days
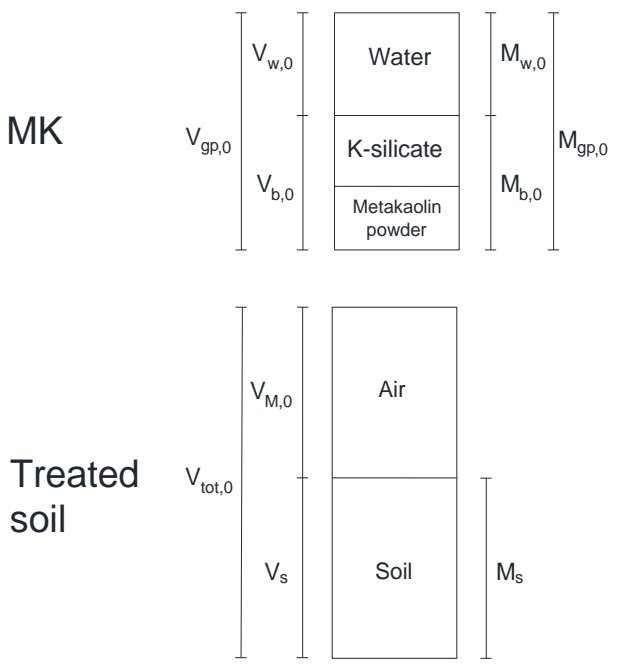

$t_{c}$ days - $D$
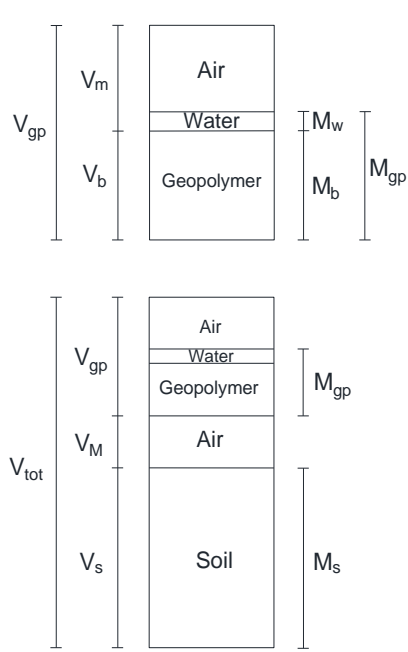

$t_{c}$ days $-W$
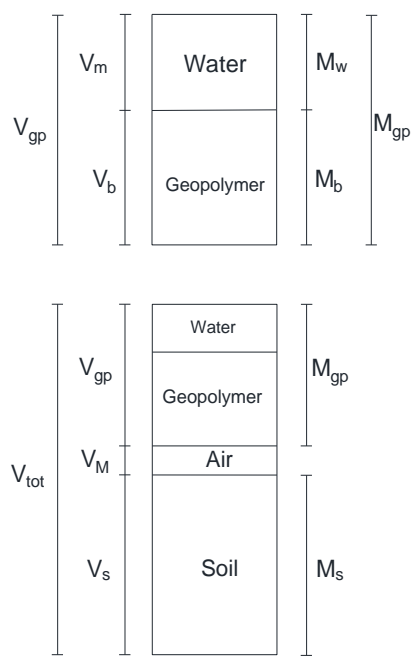

Figure 11 Phase diagrams for metakaolin geopolymer (MK) and treated soil under different curing conditions 


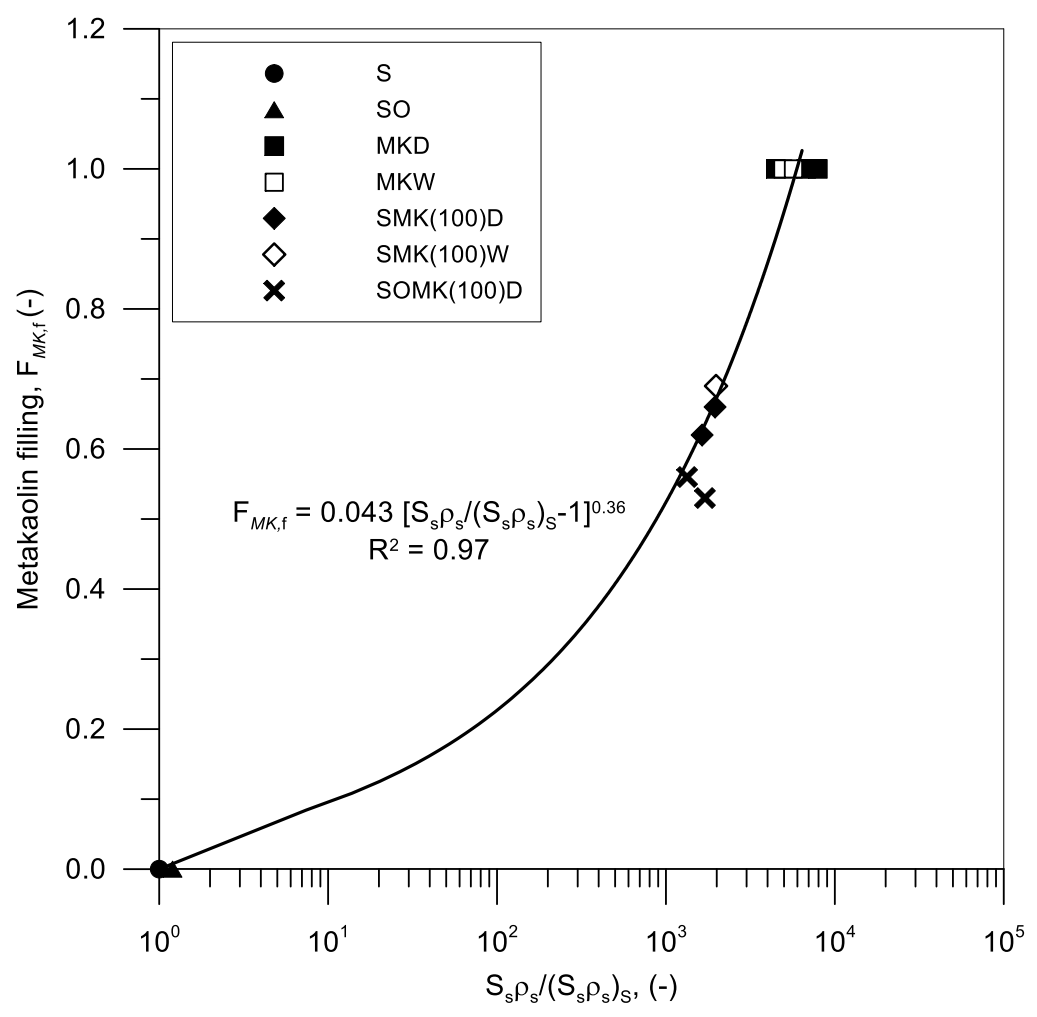

Figure 12 Correlation between Metakaolin filling and relative specific surface.

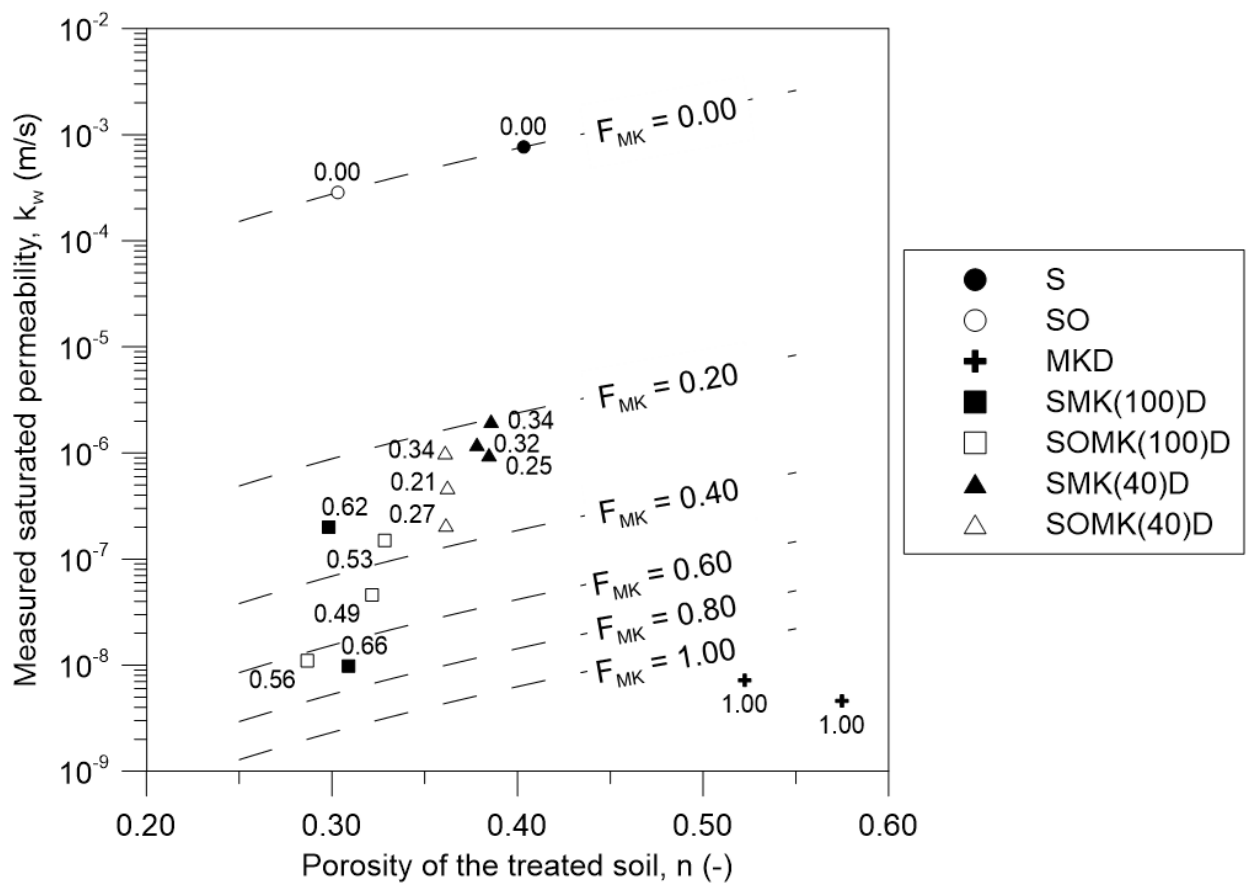

Figure 13 Permeability values as function of the final void ratio and isolines predicting the variation of the permeability with void ratio at constant specific surfaces. Metakaolin filling $F_{M K}$ as labels. 


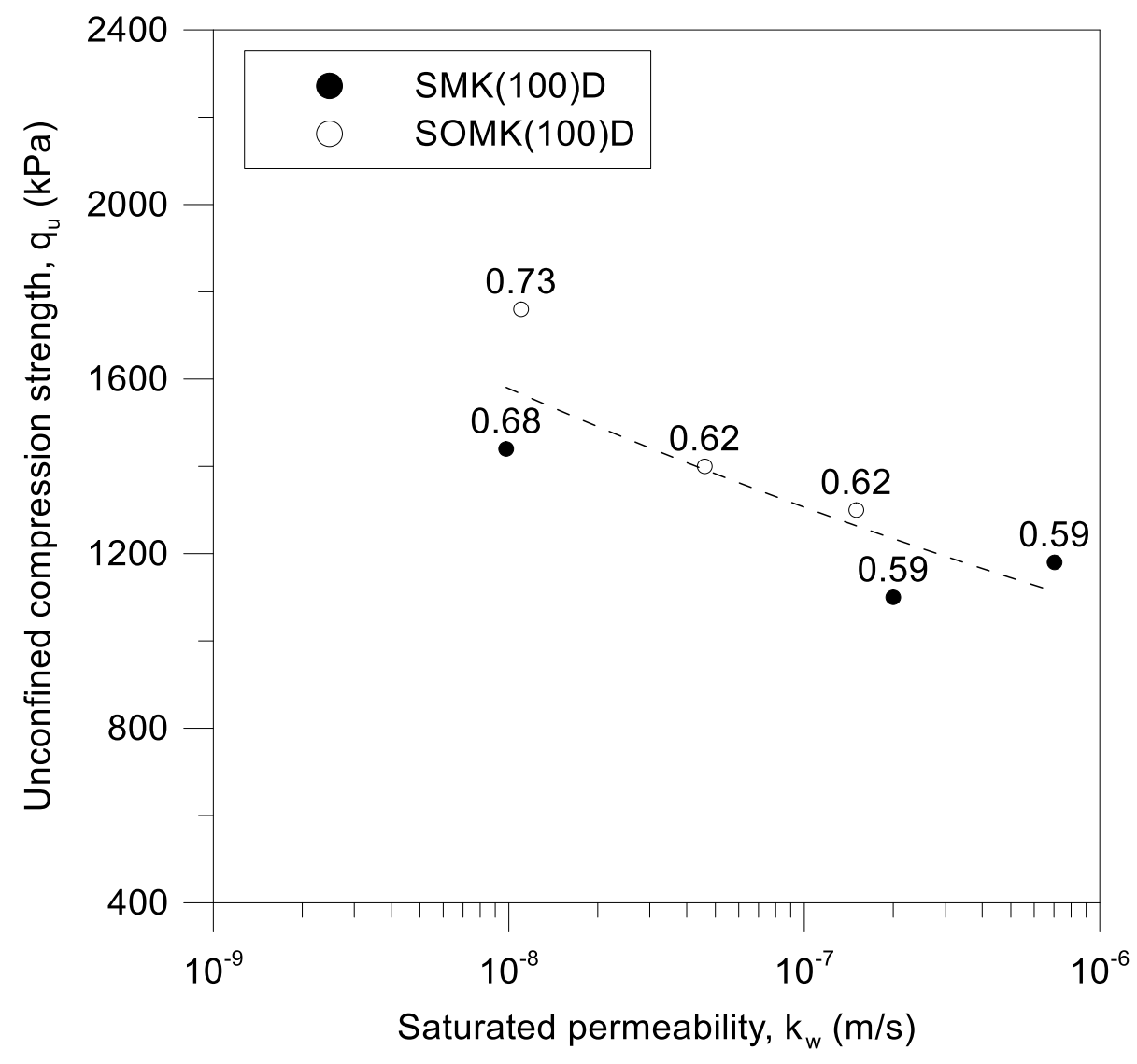

Figure 14 Trend between unconfined compressive strength and saturated permeability observed in the treated samples. Metakaolin filling $F_{M K}$ as labels

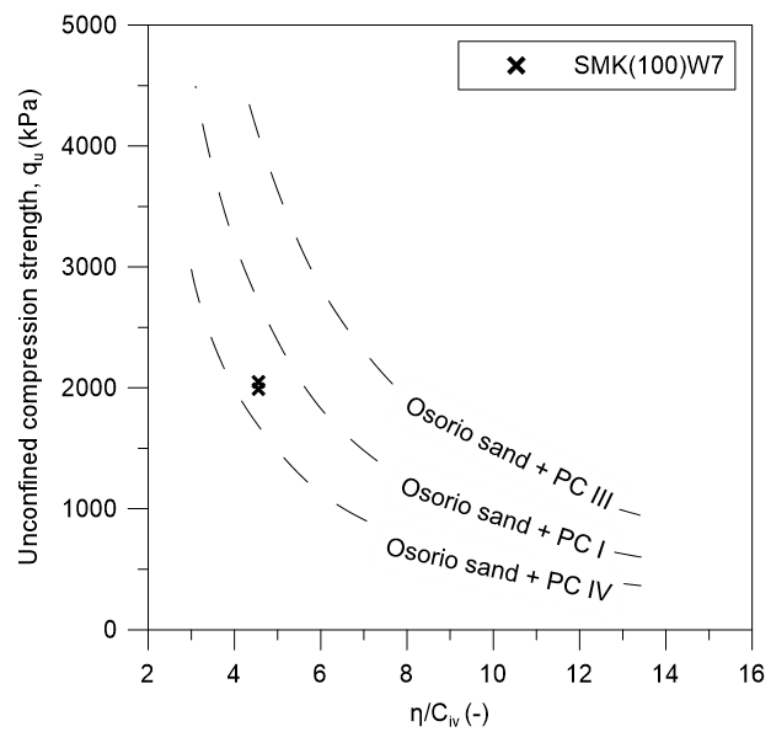

(a)

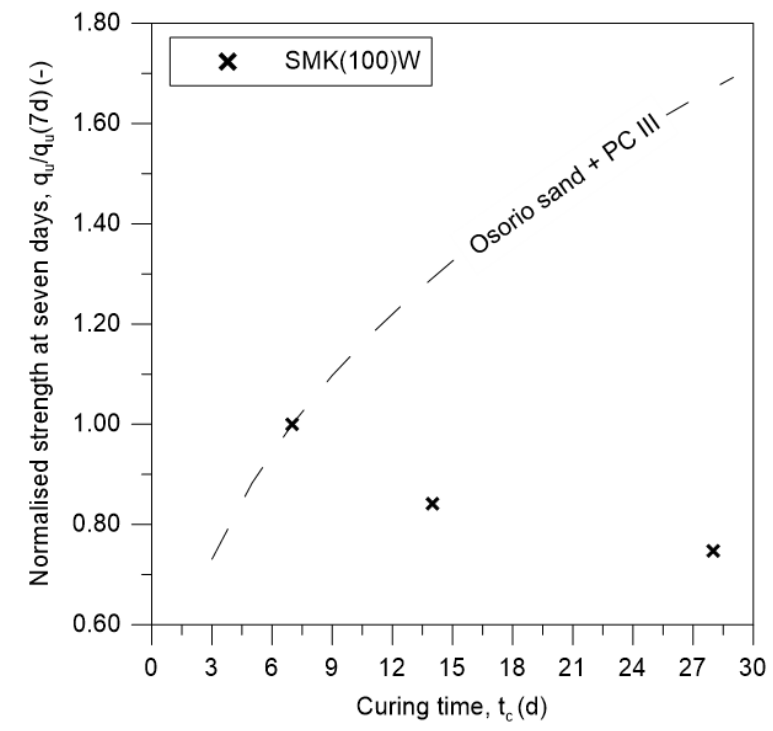

(b) 
Figure 15 Comparisons with Portland-improved sand (a) Strength vs mixture ratio $\left(\frac{\eta}{c_{i v}}\right)$ at 7 days (b) strength evolution during curing. Data for Osorio sand from Consoli et al. $(2011 ; 2016)$

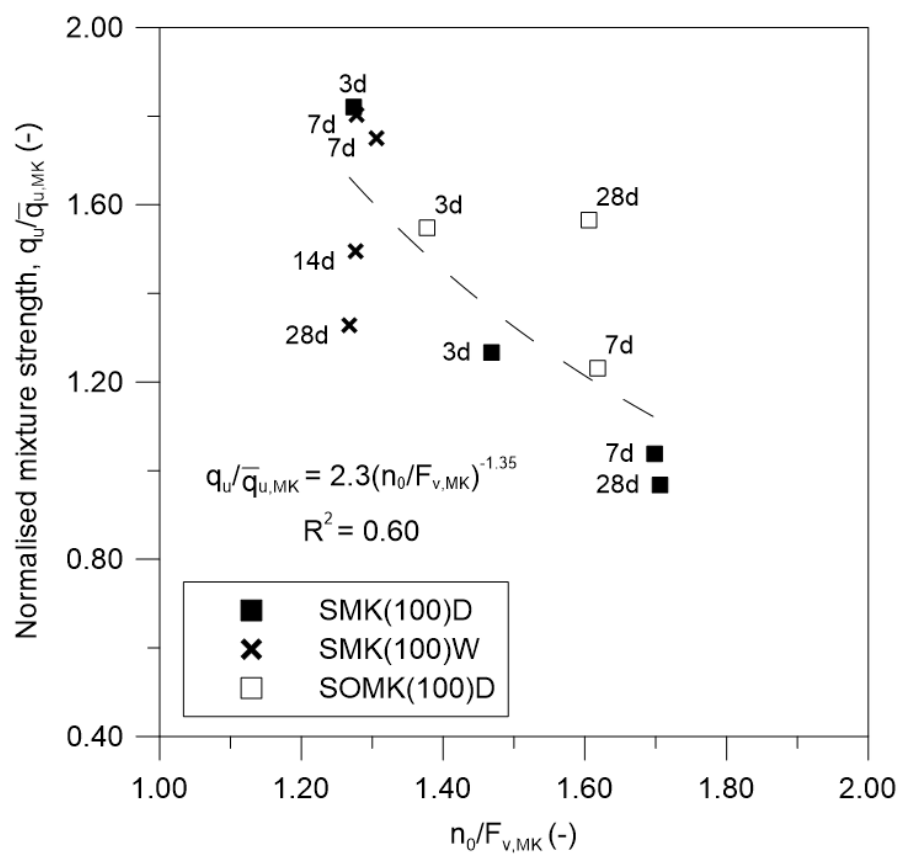

Figure 16 Trend between unconfined compressive strength and "as cured" filling ratio. Curing time as labels 


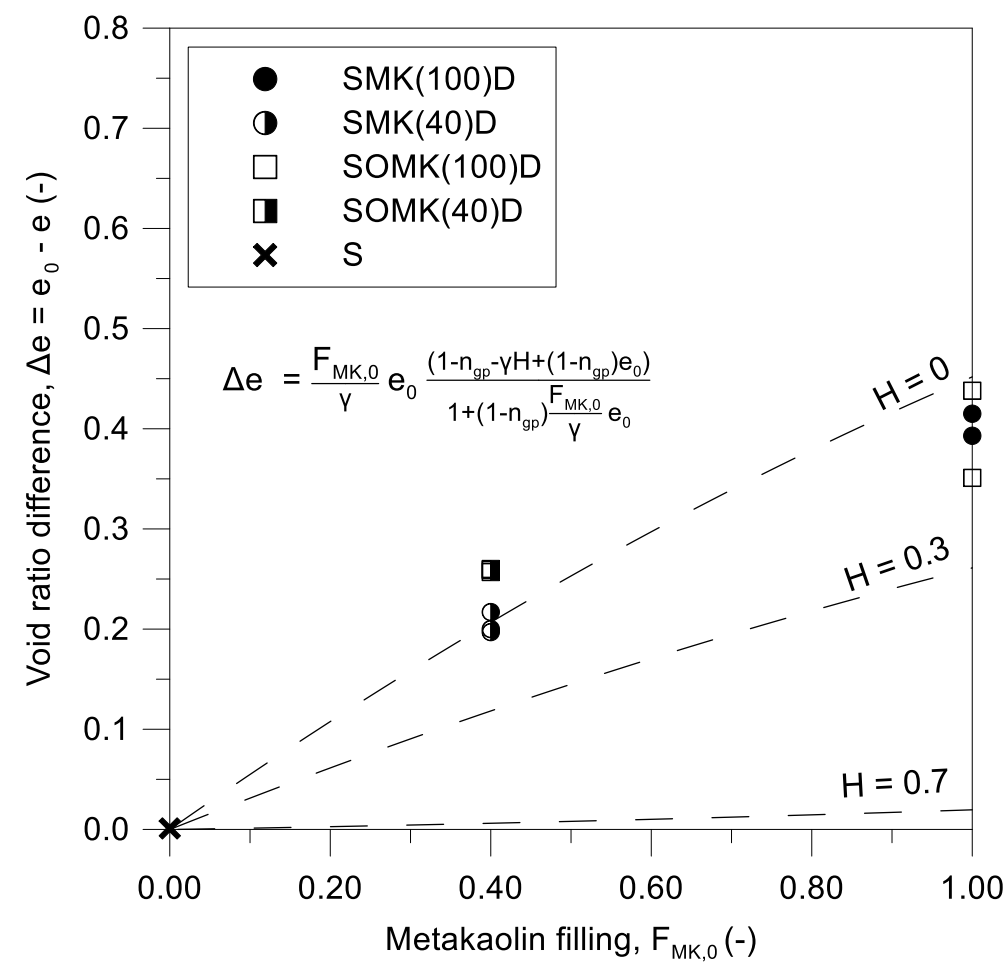

Figure 17 Evaluation of the void ratio difference by the metakaolin filling value 